\title{
Huang-Lian Jie-Du decoction: a review on phytochemical, pharmacological and pharmacokinetic investigations
}

Yiyu Qi ${ }^{1,2,3}$, Qichun Zhang ${ }^{1,2,3,4^{*}}$ and Huaxu Zhu ${ }^{1,2,3^{*}}$ (1)

\begin{abstract}
Huang-Lian Jie-Du decoction (HLJDD), a famous traditional Chinese prescription constituted by Rhizoma Coptidis, Radix Scutellariae, Cortex Phellodendri and Fructus Gradeniae, has notable characteristics of dissipating heat and detoxification, interfering with tumors, hepatic diseases, metabolic disorders, inflammatory or allergic processes, cerebral diseases and microbial infections. Based on the wide clinical applications, accumulating investigations about HLJDD focused on several aspects: (1) chemical analysis to explore the underlying substrates responsible for the therapeutic effects; (2) further determination of pharmacological actions and the possible mechanisms of the whole prescription and of those representative ingredients to provide scientific evidence for traditional clinical applications and to demonstrate the intriguing molecular targets for specific pathological processes; (3) pharmacokinetic feature studies of single or all components of HLJDD to reveal the chemical basis and synergistic actions contributing to the pharmacological and clinically therapeutic effects. In this review, we summarized the main achievements of phytochemical, pharmacological and pharmacokinetic profiles of HLJDD and its herbal or pharmacologically active chemicals, as well as our understanding which further reveals the significance of HLJDD clinically.
\end{abstract}

Keywords: Huang-Lian Jie-Du decoction, Traditional Chinese medicine, Phytochemical, Parmacological, Pharmacokinetic

\section{Background}

Herbal formula, the most popular therapeutic approach of traditional Chinese medicine (TCM), was recorded in ancient medical literature with fixed herbal components, definite curative effects, and acceptable adverse effects [1].

Huang-Lian Jie-Du decoction (HLJDD) (Orengedoku-to in Japanese and Hwangryun-Hae-Dok-Tang in Korean), a well-known classic TCM formula, was first described in Wang Tao's treatise "Wai Tai Mi Yao" in the Tang dynasty (752 A.D.). It has been a representative prescription for heat-clearing and detoxicating. Heat-clearing is to ameliorate the interior pattern or syndromes of

\footnotetext{
*Correspondence: zhangqichun@njucm.edu.cn; zhuhx@njucm.edu.cn 1 Jiangsu Collaborative Innovation Center of Chinese Medicinal Resources Industrialization, Nanjing University of Chinese Medicine, Nanjing, China
} Full list of author information is available at the end of the article exuberant heat, which is transformed from the process of external pathogens entering the internal organs. The heat is in the form of an elevation in the body temperature above normal or a subjective feeling of feverishness. Detoxicating indicates the measure to reduce the virulence and neutralize the toxicity of pathogens. Here, heat and poison are the forms of pathogens in Chinese medicines. HLJDD shows the ability to dispel the heat and poison and relieve the associated syndromes. This ability is achieved by four common crude herbs, Rhizoma Coptidis (RC) (Coptis chinensis Franch, Huang Lian), Radix Scutellariae (RS) (Scutellaria baicalensis Georgi, Huang Qin), Cortex Phellodendri (CP) (Phellodendron amurense Rupr., Huang Bo), and Fructus Gradeniae (FG) (Gardenia jasminoides Ellis, Zhi Zi) in a ratio of 3:2:2:3. According to the strict principle of "sovereign, minister, assistant

(c) The Author(s) 2019. This article is licensed under a Creative Commons Attribution 4.0 International License, which permits use, sharing, adaptation, distribution and reproduction in any medium or format, as long as you give appropriate credit to the original author(s) and the source, provide a link to the Creative Commons licence, and indicate if changes were made. The images or other third party material in this article are included in the article's Creative Commons licence, unless indicated otherwise in a credit line to the material. If material is not included in the article's Creative Commons licence and your intended use is not permitted by statutory regulation or exceeds the permitted use, you will need to obtain permission directly from the copyright holder. To view a copy of this licence, visit http://creativecommons.org/licenses/by/4.0/. The Creative Commons Public Domain Dedication waiver (http://creativecommons.org/publicdomain/zero/1.0/) applies to the data made available in this article, unless otherwise stated in a credit line to the data. 
and courier" [2], which was developed from "Huangdi's Internal Classic" to enhance the effectiveness of Chinese medicinal herbs and to reduce toxics or side effects by combining various kinds of herbs, $\mathrm{RC}$ is the sovereign medicine with the action of purging the fire from the heart and middle energizer. RS acts as the ministerial medicine, removing the heat from the lungs and eliminating the fire from the upper energizer. $\mathrm{CP}$ purges the fire from lower energizer as the assistant medicine. FG purges the triple energizers and delivers the heat back to its origin as the courier medicine [3]. The whole formula is carefully designed and precise in formation. $\mathrm{Xu}$ et al. manufactured four HLJDD variants by leaving one herb out each time and found that the integral formula exhibited the strongest therapeutic effects in the cecal ligation and puncture rats among the four variants [4]. The precise and rigorous herbal combination is believed to be advantageous over single reagent since that various components can hit multiple targets simultaneously and perform synergistic therapeutic actions [5]. Moreover, due to the lack of TCM theories such as the theoretical mechanisms of diseases, researches on decomposed recipes of Chinese herbal compounds find it difficult to reveal the complex interactions between couplet medicines.

Based on the clinical practice and inheritance of nearly a 1000 years as well as the integration of Chinese and Western medicine, the clinical application of HLJDD has gradually expanded from the diseases and symptoms of TCM to the diseases of Western medicine, and its use has also expanded to other countries besides China. With the remarkable therapeutic effects on removing excess heat and fire toxins, HLJDD plays an important role in the resolution of delirium, internal heat-related mania, insomnia, irritability, dry mouth and throat, heat-induced blood omitting, skin spots, and sore furuncle, according to Medical Secretes of an Official. This formula is also used to treat heat-pathogen-induced pyrostagnant rhinorrhagia, carbuncle, and jaundice as summarized by Prescriptions for Emerent Ref. [6]. At present, HLJDD has been widely used in the clinical practices to treat inflammation, hypertension, gastrointestinal disorders, liver and cerebrovascular diseases [7]. In a clinical study, the addition of HLJDD to yokukan-san (Japanese traditional herbal prescription) exhibited the same efficacy as aripiprazole (antipsychotics) in controlling aggressiveness of an Alzheimer's type dementia without any significant adverse reaction [8]. Another clinical study indicated that HLJDD was a possible treatment for fever of unknown origin [9]. In China, thin-layer chromatography and microscopy have been employed to establish the quality standard of Huang-Lian Jie-Du pills for decades. The contents of berberine hydrochloride and baicalin have been determined [10]. Additionally, an improved formula of HLJDD in the pill form has acquired the permission of Chinese State Food and Drug Administration to market (drug approval number Z20025356) [11]. The appearance and processing technology of Huang-Lian Jie-Du concentrated pill are shown in Fig. 1. In other Asian countries, HLJDD was approved for palliative cares and atopic dermatitis treatment by Ministry of Health, Labour and Welfare of Japan and Korean Food and Drug Administration [12, 13]. Furthermore, HLJDD has been manufactured as a powdered, freezedried water extract by Tsumura Co, Ltd in Japan [9].

More and more clinical application cases have prompted people to explore the potential pharmacological effects and possible molecular mechanisms of HLJDD by modern pharmacology and molecular biotechnology. Modern pharmacological studies indicate that HLJDD exhibits therapeutic actions in various pathological aspects, such as hyperlipidemia [14], tumor [6, 15, 16], arthritis [17-19], sepsis [20-22], cardiac damage [23], liver injury [24, 25], kidney disease [26], cerebral ischemia [27-29], type 2 diabetes mellitus (T2DM) [30, 31], Alzheimer's disease (AD) [32-34], fungal infection [35] and inflammation [36]. In the meantime, with the deepening of researches and the continuous development of technology, more and more chemical compositions of HLJDD have been discovered. The effects of drugs are based on their chemical composition. This mainstream view holds that the different pharmacological effects and clinical applications of drugs depend on the tissue distribution and concentration of their active ingredients. Therefore, pharmacokinetics (PK) should be adopted to interpret the active substance basis of HLJDD. PK has the characteristics of holistic, comprehensive and dynamic, which is similar to the holistic concept and dialectical treatment of TCM. Although there are numerous researches with positive results on HLJDD, most of them were only performed with a fraction of the total compounds. Hence, it is necessary for us to sum up these past researches which are significant in guilding further researches of HLJDD. In this review, we summarized the phytochemical, pharmacological and pharmacokinetic investigations that have been conducted in recent years.

\section{Phytochemical investigation of HLJDD}

The components of TCM formulas are complex, but not all of them have pharmacological activities. Therefore, it is of great significance to separate and identify such pharmacodynamic components. Many studies manifested that alkaloids from $\mathrm{RC}$ and $\mathrm{CP}$, flavonoids from RS and terpenes from FG are three major active components in HLJDD and therefore are regarded as markers for quality control of HLJDD [35, 37-42]. In recent years, with the progress of modern detection technology, the majority of researchers have actively explored the chemical components in HLJDD and established qualitative and quantitative 


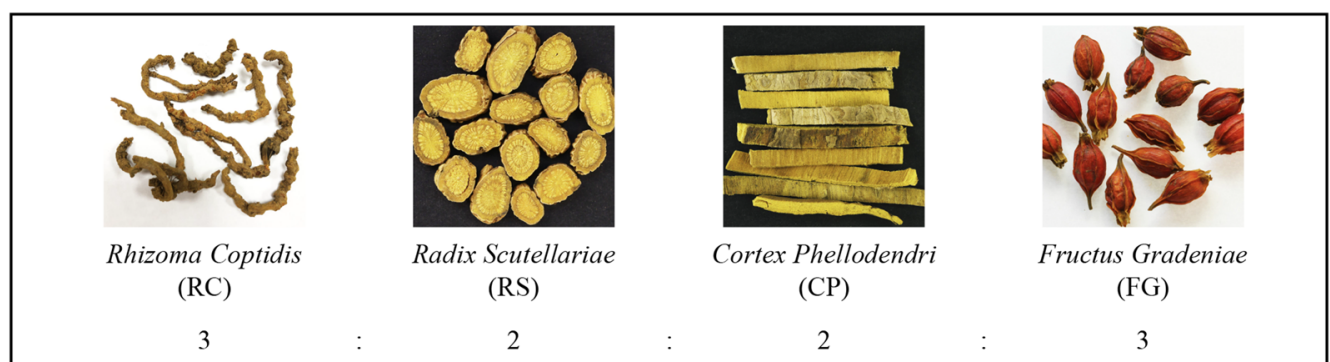

Add 10 times water, and soak for 30-60 minutes

Extract twice, 60 minutes each time, and merge filtrates

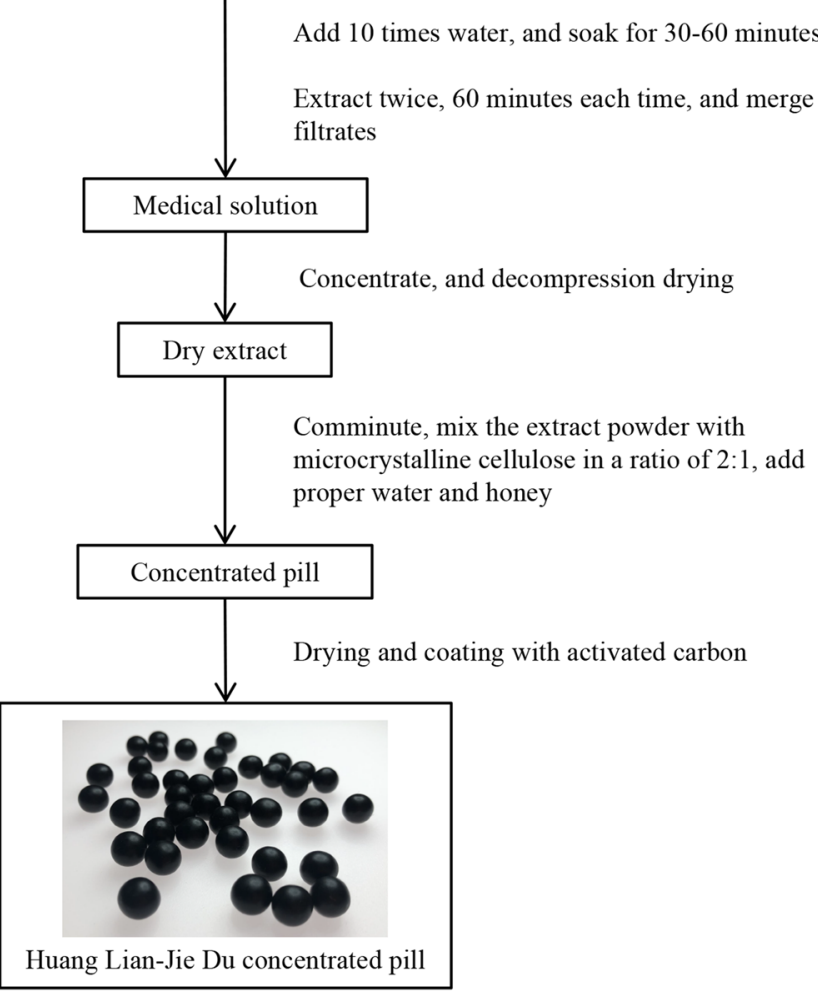

Fig. 1 Appearance and processing technology of Huang-Lian Jie-Du concentrated pill

detection methods for some of its active components. By HPLC-UV/MS, 11 major peaks in the chromatogram of HLJDD extracted by water were identified as geniposide, jatrorrhizine, palmatine, berberine, baicalin, wogonoside, baicalein, wogonin, coptisine, oroxin A, obaculactone. Among them, coptisine and obaculactone were two characteristic peaks that could distinguish CR from CP. The following quantitative analysis showed that baicalin was the most abundant, followed by geniposide, then berberine and wogonoside, respectively [43]. However, the contents of berberine, baicalin, geniposide, and baicalein in HLJDD by decocting twice under refluxing with $70 \%$ ethanol $(1: 10$ and then $1: 5, \mathrm{w} / \mathrm{v})$ were $5.12 \%, 4.17 \%, 1.65 \%$, and $0.96 \%$, respectively [44]. The reason for this difference may be related to different extraction methods and the conditions of HPLC. An effective quantitative method based on multiple wavelengths HPLC-DAD was developed for simultaneous determination of fourteen major ingredients (seven alkaloids, four flavonoids, three terpenes) in HLJDD. The total contents of these fourteen analytes reached to $70 \%$ [45]. With HPLC-UV analysis, the chemical profile of HLJDD samples was generated. HLJDD comprises four distinct constituents including berberine, palmatine, baicalin and geniposide in an approximate ratio of 3:1:1:3 [6]. Moreover, Q-Exactive was employed for the comprehensive chemical identification of HLJDD. 69 compounds, including alkaloids, flavonoids, iridoids, triterpenoid, monoterpene and phenolic acids were identified, 17 major characteristic constituents were selected as the quality control markers of HLJDD [46]. Currently, the analysis of active ingredients in HLJDD is focusing either on the prescription or on its extract, while 
quantification of that in biological samples have seldom been reported. A rapid and sensitive UHPLC-MS/MS method was developed to determinate seven main active constituents (berberine, palmatine, jatrorrhizine, baicalin, baicalein, wogonoside, and wogonin) simultaneously in atherosclerosis rat plasma after administration of HLJDD at doses of $1.5,3$, and $6 \mathrm{~g} / \mathrm{kg}$. Baicalin, baicalein, wogonoside, and wogonin were highly detected in a dose-dependent manner, while the other three components were determined in a quite low level and in a dose-independent mode [47]. In this review, the chemical components of the four herbs of HLJDD were summarized and classified, which will provide references for the separation and analysis of the chemical compositions of HLJDD.

\section{Alkaloids}

Alkaloids are nitrogen-containing organic compounds responsible for the bitter taste of HLJDD. The main sources of alkaloids in HLJDD are RC and CP, which including protoberberine-type, oxyberberine-type, aporphine-type, indolopyridoquinazoline-type, and furoquinoline-type alkaloids. Berberine [48-55] and palmatine $[49,50,52,54-56]$ were isolated from $C$. chinensis Franch, $C$. japonica Makino, $P$. chinense Schneid and P. amurense
Rupr. Coptisine [48-50, 52] and epiberberine [49, 50, 52, $56]$ were isolated from $C$. chinensis Franch. Columbamine $[49,50,54,56]$ and jatrorrhizine $[49,50,54,56]$ were isolated from C. chinensis Franch and P. amurense Rupr. The above six protoberberine-type alkaloids (Fig. 2) are considered as the main bioactive compounds of RC [57-65]. Moreover, the quantitative determination of berberine and palmatine is a very important index in the quality evaluation of CP.

The structural characteristics of alkaloids determine the low absorptions. Berberine, for example, is a quaternary ammonium alkaloid with conjugated double bonds and therefore has strong rigidity and poor solubility. Besides, berberine is the substrate of P-gp, which is an efflux transporter [47]. In addition, most berberine was excluded by the gastrointestinal tract after intragastric administration and was metabolized in a variety of pathways [66]. Hence, even long-term administration of alkaloids does not accumulate easily in the body because of their poor absorption through the intestinal wall.

\section{Flavonoids}

Flavonoids, a class of polyphenol secondary metabolites, are broadly presented in plants and fungi. Their<smiles>COc1ccc2cc3[n+](cc2c1OC)CCc1cc2c(cc1-3)OCO2</smiles><smiles>c1c2c(cc3c1OCO3)-c1cc3ccc4c(c3c[n+]1CC2)OCO4</smiles>

Coptisine<smiles>COc1cc2c(cc1OC)-c1cc3ccc(OC)c(OC)c3c[n+]1CC2</smiles><smiles>COc1cc2c(cc1OC)-c1cc3ccc4c(c3c[n+]1CC2)OCO4</smiles>
Palmatine Epiberberine<smiles>COc1cc2c(cc1O)-c1cc3ccc(OC)c(OC)c3c[n+]1CC2</smiles><smiles>COc1cc2c(cc1O)CC[n+]1cc3c(OC)c(OC)ccc3cc1-2</smiles>

Fig. 2 Structures of representative alkaloids isolated from HLJDD Jatrorrhizine 
basic structure consists of $\mathrm{C}_{6}-\mathrm{C}_{3}-\mathrm{C}_{6}$ ring with different substitution patterns to produce a series of subclass compounds, including flavones, flavonols, chalcones, dihydrochalcones, aurones, flavanones, dihydroflavonols, and anthocyanins. Flavonoids are the most abundant and biologically active ingredients of RS, for more than 40 flavonoids have been discovered so far from RS in the form of aglycones and glycosides [67]. Among them, baicalin [68, 69], baicalein [68, 69], wogonoside [68, 69], and wogonin [68-70] (Fig. 3) are the characteristic chemical components of RS. By HPLC analysis, the ratio of the above four flavonoids in RS was $10.11 \%, 5.41 \%, 3.55 \%$ and $1.3 \%$, respectively [71].

The absorptions of flavonoids were relatively better than the alkaloids. Flavonoids are easy to combine with glucuronic acid or sulfuric acid to form two-phase metabolism, thereby their plasma concentration-time curves showed obvious bimodal phenomena [72].

\section{Iridoids and iridoid glycosides}

The major effective constituents of FG are iridoids and iridoid glycosides, such as genipin [73], geniposide [74-76], gardenoside [74, 76], shanzhiside [74, 76], and geniposidic acid [77] (Fig. 4). Among these components, geniposide and gardenoside, in particular, have very similar chemical compositions, with a difference of only one oxygen atom [77]. These compounds

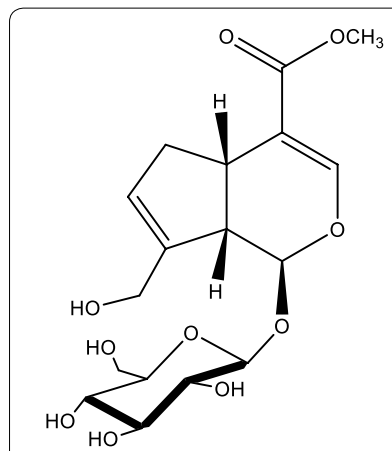

Geniposide

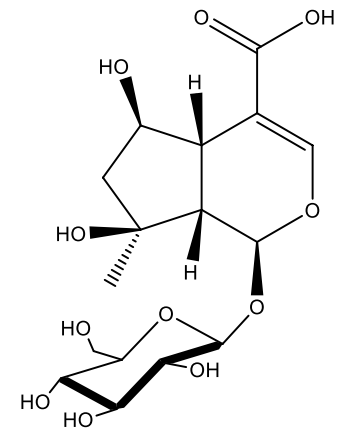

Shanzhiside

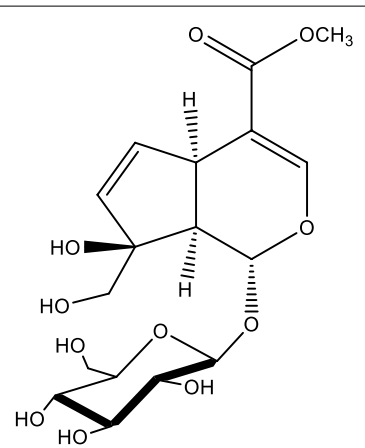

Gardenoside

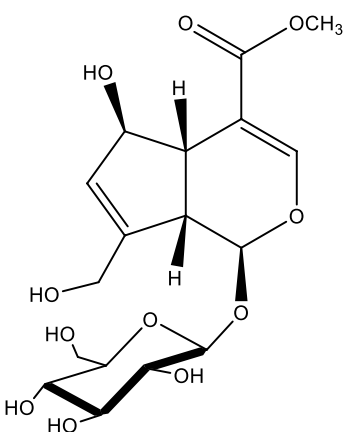

Scandoside methyl ester

Fig. 4 Structures of representative iridoid glycosides isolated from HLJDD<smiles>C[C@@H]1[C@@H](C(=O)O)O[C@H](Oc2cc3oc(-c4ccccc4)cc(=O)c3c(O)c2O)[C@@H](O)[C@@H]1O</smiles>

Baicalin<smiles>O=c1cc(-c2ccccc2)oc2cc(O)c(O)c(O)c12</smiles>

Baicalein<smiles>COc1c(O[C@@H]2O[C@H](C(=O)O)[C@@H](O)[C@H](O)[C@H]2O)cc(O)c2c(=O)cc(-c3ccccc3)oc12</smiles>

Wogonoside<smiles>COc1c(O)cc(O)c2c(=O)cc(-c3ccccc3)oc12</smiles>

Fig. 3 Structures of representative flavonoids isolated from HLJDD 
are responsible for the biological activities of FG, and their accurate and effective purification is of great significance for the quality control of this drug and its formulations. The content of iridoid glycosides may vary from different processing methods at about 2.65-7.23\% [78]. A study quantified the content of geniposide, gardenoside, and geniposidic acid from different origins in China with $60.88 \pm 11.47 \mathrm{mg} / \mathrm{g}, 56.33 \pm 17.55 \mathrm{mg} / \mathrm{g}$, and $2.61 \pm 0.91 \mathrm{mg} / \mathrm{g}$, respectively. Meanwhile, their average content were $52.80 \pm 12.93 \mathrm{mg} / \mathrm{g}, 42.50 \pm 13.21 \mathrm{mg} / \mathrm{g}$, and $2.88 \pm 2.19 \mathrm{mg} / \mathrm{g}$, respectively, measured from different regions in Korea [77].

\section{Other chemical components}

Lignans, polyphenolic substances derived from phenylalanine via dimerization of substituted cinnamic alcohols, are also abundant in RC. They have various structures, including benzofurans, furofurans, tetrahydrofurans, and arylnaphthanlenes [70, 79-81]. Moreover, phenylpropanoids [70, 80], phenolic compounds, saccharides, and steroids have been isolated from RC [50, 51, 80-83]. It was reported that diterpenoids $[84,85]$ and essential oils [86] were also found in RS. In addition to alkaloids, CP also contains sterols, esters, triterpenes and other compounds [87-90]. Triterpenes, monoterpenoids, carotenoids, phenolic acids and volatile ingredients were discovered in FG [91-93].

\section{Pharmacological effects}

With the rapid development of modern pharmacology and biological technologies, increasing evidence has demonstrated the pleiotropic therapeutic functions of HLJDD on tumors, hepatic diseases, inflammations, allergies, blood lipid and glucose disorders, central nerve system diseases, bacterial infections, and intestinal flora disturbances (Table 1).

\section{Anti-tumor}

The ancient Chinese medical monograph "Zhong-ZangJing" recorded some descriptions of cancer-like symptoms such as "Yong, Yang, Chuang and Zhong", which are caused by retention of various pathogens including heat and dampness. Tumor growth involves induction of cellcycle progression, avoidance of apoptosis, and activation of the cell survival pathway [94]. Modern studies indicated that HLJDD could disrupt these processes, to suppress the tumor growth in vivo, and inhibite proliferation of cancer cells in vitro.

In a hepatocellular carcinoma xenograft murine model, HLJDD was shown to suppress the xenografted growth in dose-dependent manner. The inhibitory effect of HLJDD may be due to the activation of eukaryotic elongation factor-2 kinase (eEF2K) and inactivation of eEF2. The activation of AMP-activated protein kinase (AMPK) signaling may be responsible for the eEF2K induction [6]. eEF2 is an essential protein for the elongation of nascent peptide [95]. The inactivation of eEF2 suppresses the synthesis of nascent protein, which supports the proliferation of the cancer cells [96]. The AMPK activation was reported to inhibit the mammalian target of rapamycin (mTOR) activity, followed by blockade of mTOR-mediated eEF2K phosphorylation [97]. Geniposide, baicalin, berberine and palmatine could induce phosphorylated eEF2 expression in Hep G2 and MHCC97L cells, which suggested that these four compounds could target on eEF2 [6]. However, their inhibitory effects on eEF2 activity have not been reported. Berberine and baicalin may be the two main components targeting AMPK in HLJDD, since they have been reported as AMPK activators [98, 99]. It would be quite interesting to investigate the precise mechanism of the combination effect of active compounds in HLJDD. Another study on HLJDD in the treatment of hepatocellular carcinoma revealed the mutiple underlying mechanisms, including induction of apoptosis, blockade of cell cycle progression by regulating cell-cycle-related factor, modulation of the B cell CLL/ lymphoma 2 family proteins to favor programmed cell death, triggering of the mitochondrial pathway through membrane depolarization and caspase- 9 activation, and inhibition of nuclear factor-kappa B (NF- $\mathrm{KB}$ ) survival signaling pathway [100]. RS was responsible for the suppressive effect of HLJDD on myeloma cell proliferation, since $\mathrm{RS}$ alone exhibited stronger growth inhibition $\left(\mathrm{IC}_{50}\right.$ $30 \mathrm{ng} / \mathrm{mL})$ than HLJDD $\left(\mathrm{IC}_{50} 70 \mathrm{ng} / \mathrm{mL}\right)$ on U266 cells. In addition, baicalein showed the strongest growth inhibition with an $\mathrm{IC}_{50}$ of $28 \mu \mathrm{M}$; while the $\mathrm{IC}_{50} \mathrm{~s}$ of baicalin and wogonin, another two major flavonoids of RS, were greater than $200 \mu \mathrm{M}$. Baicalein inhibited the survival of MPC $-1^{-}$immature myeloma cells in vitro, and induced apoptosis in myeloma cell lines by inhibiting the activity of NF- $\mathrm{kB}$ and thereby blocking the degradation of inhibitor-kappa B-alpha (IкB- $\alpha)$. Further, induction of apoptosis by HLJDD, RS or baicalein may be considered to be involved in the mitochondria-mediated pathway, because the rapid loss of mitochondrial membrane potential was confirmed, followed by enhanced release of cytochromes $c$ and subsequent activation of caspase- 9 and caspase-3 [101]. In mitochondria pathway, the activity of NF- $\kappa B$ is considered to be pivotal, which modulates the expression and function of B-cell CLL/lymphoma 2 family proteins in the mitochondria $[102,103]$. These findings, consistent with previous studies, suggested that HLJDD and its active components exert therapeutic effects on different tumors through almost the same pathway. The molecular mechanisms of HJDD against tumor are shown in Fig. 5. 
Table 1 Pharmacological actions and therapeutic or regulatory mechanisms of HLJDD

\begin{tabular}{|c|c|c|c|}
\hline Pharmacological actions & Model & Mechanisms & Refs. \\
\hline \multirow[t]{2}{*}{ Anti-tumor } & Hepatocellular carcinoma xenograft murine & $\begin{array}{l}\text { Suppressing xenografted growth by inactivating eEF2 } \\
\text { through the activation of AMPK signaling }\end{array}$ & {$[6]$} \\
\hline & $\begin{array}{l}\text { Hepatocellular carcinoma xenograft } \\
\text { Hep G2 } \\
\text { PLC/PRF/5 }\end{array}$ & $\begin{array}{l}\text { Inducing apoptosis } \\
\text { Blocking cell cycle progression by regulating cell- } \\
\text { cycle-related factor (p21/WAF1, cyclin B1, cyclin A, } \\
\text { Cdc25C, and Cdc2) } \\
\text { Promoting programmed cell death by modulating } \\
\text { Bcl-2 } \\
\text { Triggering mitochondrial pathway through mem- } \\
\text { brane depolarization and caspase-9 activation } \\
\text { Inhibiting NF-kB survival signaling pathway }\end{array}$ & {$[100]$} \\
\hline \multirow[t]{3}{*}{ Hepatoprotection } & Thioacetamide & Restoring redox system, gut flora, and urea cycle & {$[24]$} \\
\hline & Bile duct ligation & $\begin{array}{l}\text { Restoring redox system, gut flora, Kreb's cycle, and } \\
\text { oxidation of branchedchain amino acids }\end{array}$ & {$[24]$} \\
\hline & Bile duct ligation & $\begin{array}{l}\text { Ameliorating energy metabolism, amino acid } \\
\text { metabolism and gut microbiota metabolism } \\
\text { Protecting oxidative injury }\end{array}$ & {$[25]$} \\
\hline \multirow[t]{9}{*}{ Anti-inflammatory } & $\begin{array}{l}\text { Carrageenan-induced rat air pouch } \\
\text { A23187-stimulated peritoneal macrophages } \\
\text { LPS-stimulated RAW } 264.7 \text { macrophages }\end{array}$ & $\begin{array}{l}\text { Inhibiting inflammatory responses and eicosanoids } \\
\text { generation from different lipoxygenases }\end{array}$ & {$[106]$} \\
\hline & $\begin{array}{l}\text { Carrageenan-induced mice paw edema } \\
\text { LPS-stimulated RAW } 264.7 \text { macrophages }\end{array}$ & Reducing oxidative injury & {$[44]$} \\
\hline & Collagen-induced arthritis rats & $\begin{array}{l}\text { Regulating fatty acid oxidation and arachidonic acid } \\
\text { metabolism }\end{array}$ & {$[19]$} \\
\hline & LPS-stimulated RAW 264.7 macrophages & $\begin{array}{l}\text { Suppressing the production of inflammatory media- } \\
\text { tors via inactivation of NF-KB and MAPKs, and degra- } \\
\text { dation of } 1 \mathrm{kBa}\end{array}$ & {$[108]$} \\
\hline & $\begin{array}{l}\text { Cecal ligation and puncture-induced septic model } \\
\text { rats }\end{array}$ & $\begin{array}{l}\text { Enhancing cholinergic anti-inflammatory pathway } \\
\text { Inhibiting HMGB-1/TLR4/NF-KB signaling pathway }\end{array}$ & {$[4]$} \\
\hline & $\begin{array}{l}\text { Cecal ligation and puncture-induced septic model } \\
\text { rats }\end{array}$ & $\begin{array}{l}\text { Suppressing the production of proinflammatory } \\
\text { cytokines } \\
\text { Reversing the shift from Th1 to Th2 response and pro- } \\
\text { mote Th1/Th2 balance toward Th1 predominance } \\
\text { linhibiting Th17 activation }\end{array}$ & {$[112]$} \\
\hline & $\begin{array}{l}\text { 2,4-dinitrochlorobenzene-induced atopic dermatitis } \\
\text { mice } \\
\text { LPS-stimulated RAW } 264.7 \text { macrophages }\end{array}$ & Inhibiting MAPKs/NF-kB pathway & {$[115]$} \\
\hline & LPS-induced gingivitis rats & Inhibiting AMPK and ERK1/2 pathway & {$[116]$} \\
\hline & LPS-induced acute kidney injury mice & $\begin{array}{l}\text { Inhibiting NF-KB and MAPK activation } \\
\text { Activating Akt/HO-1 pathway } \\
\text { Ameliorating disturbances in oxidative stress and } \\
\text { energy metabolism }\end{array}$ & {$[26]$} \\
\hline Anti-allergy & Antigen-induced RBL-2H3 cells & $\begin{array}{l}\text { Suppressing allergic mediators via inactivation of } \\
\text { MAPKs and Lyn pathway }\end{array}$ & {$[108]$} \\
\hline \multirow[t]{3}{*}{ Modulation of blood lipid } & $\begin{array}{l}\text { ApoE(-/-) mice } \\
\text { Primary bone marrow-derived macrophage } \\
\text { Foam cells }\end{array}$ & $\begin{array}{l}\text { Regulating the functional differentiation of mono- } \\
\text { cytes, macrophages, and foam cells }\end{array}$ & {$[119]$} \\
\hline & High-fat diet-induced hyperlipidemia rats & $\begin{array}{l}\text { Activating the activityof lipid metabolism enzyme } \\
\text { Enhancing the expressions of LDLR and PPAR Y } \\
\text { mRNAs }\end{array}$ & {$[14]$} \\
\hline & High-fat diet and streptozotocin-induced T2DM rats & Inhibiting the activity of intestinal pancreatic lipase & {$[30]$} \\
\hline \multirow[t]{2}{*}{ Modulation of blood glucose } & streptozotocin-induced T2DM rats & $\begin{array}{l}\text { Enhancing GLP-1 secretion in gut to promoting insu- } \\
\text { lin secretion and improving function of } \beta \text { cell }\end{array}$ & {$[120]$} \\
\hline & $\begin{array}{l}\text { Min6 cells } \\
\mathrm{NCl}-\mathrm{H} 716 \text { cells }\end{array}$ & $\begin{array}{l}\text { Elevating intracellular cAMP levels to promote GLP-1 } \\
\text { secretion and insulin secretion } \\
\text { Increasing } \beta \text { cell mass through hyperplasia and } \\
\text { hypertrophy }\end{array}$ & {$[121]$} \\
\hline
\end{tabular}


Table 1 (continued)

\begin{tabular}{|c|c|c|c|}
\hline Pharmacological actions & Model & Mechanisms & Refs. \\
\hline \multirow[t]{6}{*}{ Central nervous system diseases } & MCAO rats & $\begin{array}{l}\text { Inhibiting neuron apoptosis and enhancing its } \\
\text { proliferation through activating PI3K/Akt signaling } \\
\text { pathway and HIF-1a }\end{array}$ & {$[28]$} \\
\hline & MCAO rats & $\begin{array}{l}\text { Inducing protective autophagy through the regula- } \\
\text { tion of MAPK signals }\end{array}$ & {$[126]$} \\
\hline & MCAO rats & $\begin{array}{l}\text { Ameliorating the disordered metabolisms in energy, } \\
\text { membrane and mitochondrial, amino acid and } \\
\text { neurotransmitter } \\
\text { Alleviating the inflammatory damage and the oxida- } \\
\text { tive stress from ROS } \\
\text { Recovering the destructed osmoregulation }\end{array}$ & {$[127]$} \\
\hline & SAMP8 & $\begin{array}{l}\text { Modulating gene expressions in signal transduction } \\
\text { (Dusp12, Rps6ka1, Rab26, Penk1, Nope, Leng8, } \\
\text { Syde1, Phb, Def8, Ihpk1, Tac2, Pik3c2a), protein } \\
\text { metabolism (Ttc3, Amfr, Prr6, Ube2d2), cell growth } \\
\text { and development (Ngrn, Anln, Dip3b, Acrbp), } \\
\text { nucleic acid metabolism (Fhit, Itm2c, Cstf2t, Ddx3x, } \\
\text { Ercc5, Pcgfr6), energy metabolism (Stub1, Uqcr, } \\
\text { Nsf), immune response (C1qb), regulation of tran- } \\
\text { scription (D1ertd161e, Gcn5l2, Ssu72), transporter } \\
\text { (Slc17a7, mt-Co1), nervous system development } \\
\text { (Trim3), and neurogila cell differentiation (Tspan2) }\end{array}$ & {$[132]$} \\
\hline & APPswe/PS1dE9 mice & $\begin{array}{l}\text { Ameliorating neuroinflammation and sphingolipid } \\
\text { metabolic disorder }\end{array}$ & {$[34]$} \\
\hline & HEK 293 cells & Inhibiting indoleamine 2,3-dioxygenase activity & {$[133]$} \\
\hline \multirow[t]{3}{*}{ Anti-infection } & Candida albicans & $\begin{array}{l}\text { Inhibiting formation of hyphae and colony morpholo- } \\
\text { gies through downregulating the expression of } \\
\text { HWP1, ALS3, UME6 and CSH1 }\end{array}$ & {$[136]$} \\
\hline & Pseudomonas aeruginosa & $\begin{array}{l}\text { Reducing pyocyanin pigment, elastolytic activity, } \\
\text { proteolytic activity, biofilm formation, and bacterial } \\
\text { motility }\end{array}$ & {$[137]$} \\
\hline & H1N1 & Inhibiting NA activity & {$[139]$} \\
\hline Modulation of microbiota & High-fat diet and streptozotocin-induced T2DM rats & $\begin{array}{l}\text { Ameliorating hyperglycemia and restoring the } \\
\text { disturbed gut microbiota structure and function } \\
\text { through increasing short chain fatty acids-produc- } \\
\text { ing bacteria while reducing conditioned patho- } \\
\text { genic bacteria }\end{array}$ & {$[143]$} \\
\hline
\end{tabular}

The role of TCM in the treatment of tumors is often auxiliary. Combined with chemical drugs, it can increase the efficacy on one hand, and reduce the side effects on the other hand, while the researches in these aspects need to be further studied.

\section{Hepatoprotection}

Liver is vital for bile formation, amino acid utilization and ammonia detoxification, and is also the organ where glycolysis, gluconeogenesis, and the synthesis of certain plasma proteins happen [104]. In the liver, the toxic chemicals are commonly metabolized by cytochrome P450, namely first-pass effect. Hence, its detoxification ability would be attenuated due to pathological damage. In TCM, liver is depicted as an organ susceptible to heat and toxins, due to which dysfunction of liver is observed.

HLJDD is rich in bioactive alkaloids, flavonoids, iridoid glycosides, and polyphenols, could restore the balance of the disturbed metabolic status common in two cholestasis injuries, e.g. redox system and gut flora, urea cycle in thioacetamide model, and Kreb's cycle and oxidation of branchedchain amino acids in bile duct ligation model, respectively [24]. These findings are consistent with a previous study that also used bile duct ligation to induce cholestatic liver injury [25]. The protection of single or combination use of berberine and HLJDD on acute liver injury induced via cecal ligation and puncture were to explore the herb-drug interactions of them in a holistic way. Livers of sham-operated group, treatment groups of berberine, HLJDD and their co-administration displayed no obvious histopathological changes. Both histamine and trimethylamine $N$-oxide were exclusively decreased by the treatments of HLJDD with or without berberine. Glutathione and carnosine were significantly increased after HLJDD and the combination treatment. Metabolomics analysis revealed that HLJDD had better 


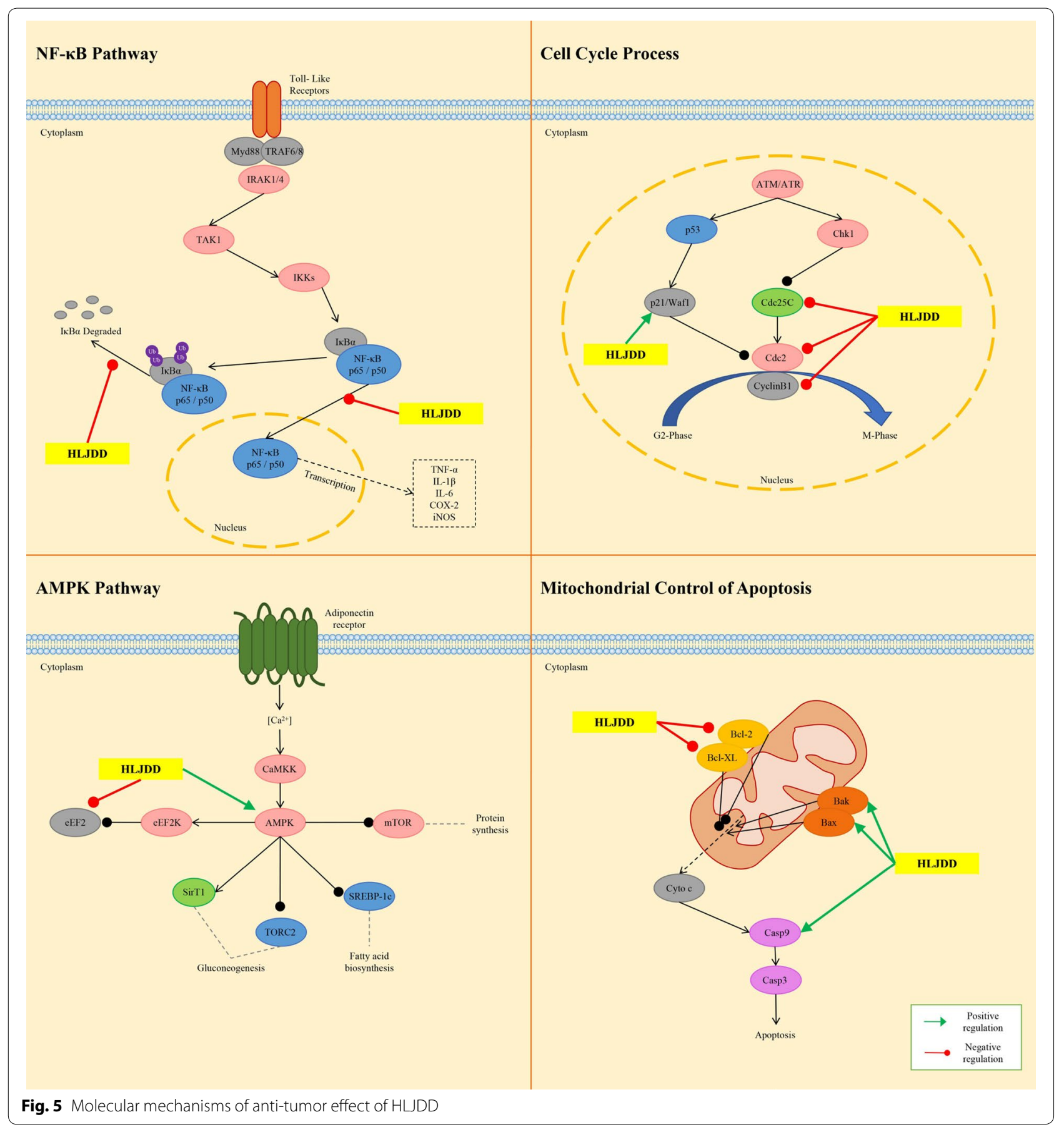

anti-inflammatory, anti-bacterial, and anti-oxidative effects than berberine alone. The single use of berberine had an inferior ability to HLJDD in restoring the whole disturbed metabolism of model rats [105].

\section{Anti-inflammatory and anti-allergy}

It is believed in TCM that endogenous and exogenous heat and toxins are pathogenic mechanisms of inflammation. To some extent, inflammatory and allergic mediators, as well as inflammatory factors generated by inflammations and allergies are recongnized as toxins leading to the heat syndromes appearing in the context of inflammatory and allergic responses.

Oral administration of HLJDD at a dose of $150 \mathrm{mg} /$ $\mathrm{kg}$ and $300 \mathrm{mg} / \mathrm{kg}$ significantly inhibited the inflammatory responses in carrageenan injected rat air pouches, 
with the inhibition ratio for exudate volume being $22.1 \%$ and $25.7 \%$, and for leucocyte influx $26.4 \%$ and $36.2 \%$, respectively. It also greatly reduced the production of nitric oxide (NO) and leukotriene B (4) in vivo without any influence on the biosynthesis of cyclooxygenasederived eicosanoids. However, eicosanoids derived from different lipoxygenases (LOs) were markedly inhibited by HLJDD in calcium ionophore A23187-stimulated peritoneal macrophages [106]. Further experiments on cell-free purified enzymes showed that RC and RS were responsible for the suppressive effect of HLJDD on eicosanoid generation. Baicalein and baicalin derived from RS showed significant inhibition on 5-LO and 15-LO, and coptisine derived from $\mathrm{RC}$ showed medium inhibition on leukotriene $\mathrm{A}_{4}$ hydrolase. Moreover, 6 pure components including baicalein, baicalin, wogonoside, wogonin, coptisine, and magnoflorine could inhibite the generation of eicosanoid in rat peritoneal macrophages via LO pathway [11]. In lipopolysaccharide (LPS)-treated RAW 264.7 macrophages, the NO production $[44,106]$, the mRNA expression of inducible nitric oxide synthase and several chemotactic factors (CCL3, CCL4, CCL5 and CXCL2) were suppressed by HLJDD [106]. Moreover, HLJDD also decreased the levels of malondialdehyde, prostaglandin E2, interleukin-6 (IL-6), IL-10, and tumor necrosis factoralpha (TNF- $\alpha$ ), and increased the activity of superoxide dismutase in this model [44]. The results of exploring the material base for the anti-inflammatory activity of HLJDD showed that its two fractions had different effects on these parameters. On one side, HLJDD-1 (iridoids and flavonoid glycosides) showed higher antioxidant activity than HLJDD-2 (alkaloids and flavonoid aglycones) as supported by decreasing the level of malondialdehyde and enhancing the activity of superoxide dismutase. On the other side, HLJDD-2 has a more obvious inhibitory effect on NO and IL-6 than HLJDD-1. Moreover, most of the four typical compounds (geniposide, baicalin, berberine and baicalein) of HLJDD showed weaker effects on these parameters than HLJDD and the two fractions, suggesting that these compounds may have synergistic anti-inflammatory interactions [44]. In collagen-induced arthritis rats, the combination of 13 components (geniposide, coptisine, phellodendrine, jatrorrhizine, magnoflorine, palmatine, berberine, baicalin, chlorogenic acid, crocin, wogonoside, baicalein, and wogonin) of HLJDD exhibited similar pharmacological activities as HLJDD aqueous extracts in ameliorating the symptoms of arthritis, preventing joint damage, and reducing the serum levels of TNF- $\alpha$, interferon-gamma and IL-17 [107]. HLJDD and its constituents combination have been shown to regulate fatty acid oxidation and arachidonic acid metabolism in collagen-induced arthritis rats [19]. In addition, the disturbed urinary levels of succinic acid, citric acid, creatine, uridine, pantothenic acid, carnitine, phenylacetylglycine, allantoin and plasma levels of phenylpyruvic acid in model rats were demonstrated to be restored by HLJDD. Meanwhile, the combination of HLJDD was able to recover the disordered urinary levels of citric acid, creatine, pantothenic acid, carnitine, phenylacetylglycine and plasma levels of uric acid, L-histidine, and L-phenylalanine in model rats [17]. Taken together, the 13 constituents' combination may represent the effective-composite of HLJDD. More importantly, HLJDD is beneficial in suppressing inflammation processes by synergistically acting on various components that on multiply target point. Hence, further researches elucidating the mode of action of these ingredients would give an insight into the use of HLJDD for its anti-inflammatory activity. The results of in vitro experiments indicated that the ethanolic extract of HLJDD exerted significant anti-inflammatory and anti-allergic effects through suppressing the production of inflammatory mediators (NO, IL-1 $\beta$, IL-4, monocyte chemoattractant protein-1and granulocyte-macrophage colony stimulating factor) via the NF- $\mathrm{BB}$ and mitogenactivated protein kinases (MAPKs) inactivation and IkB- $\alpha$ degradation in the LPS-stimulated RAW 264.7 cells, and allergic mediators (IL-4, TNF- $\alpha$, and monocyte chemoattractant protein-1) by inactivating the MAPKs and Lyn pathway in antigen-induced RBL-2H3 cells [108].

Based on its powerful anti-inflammatory ability, a large number of studies have proved that HLJDD is an effective prescription for treating various inflammatory diseases, such as inflammatory bowel disease [109], gastritis $[110,111]$, and sepsis $[4,22,112-114]$. Sepsis is a clinical syndrome characterized by systemic inflammation. In the experimental septic model rats induced by cecal ligation and puncture, HLJDD treatment suppressed the production of proinflammatory cytokines (TNF- $\alpha$, IL-1, IL-6, and IL-17A), reversed the shift from T-helper (Th) 1 to Th2 response and promote Th1/Th2 balance toward Th1 predominance, and inhibited Th17 activation [112]. In addition, L-proline, L-valine, oleic acid, carnitine, palmitoylcarnitine, arachidonic acid, and arachidic acid were reversed by HLJDD, while docosahexaenoic acid, eicosapntemacnioc acid, and prostaglandin E3 were further elevated by HLJDD in the septic condition [22]. The strong therapeutic effects of HLJDD in septic models may be ascribed to its significant enhancement of cholinergic anti-inflammatory pathway and inhibition of high mobility group protein B1/Toll-likereceptor 4/NF-kB signaling pathway [4]. Sepsis often result in endorgan dysfunction, such as acute kidney injury. HLJDD and its component herbs could effectively inhibit LPS-induced acute kidney injury in mice by inhibiting $N F-\kappa B$ and MAPK activation and activating the Akt/HO-1 pathway, and by significantly ameliorating disturbances in 
oxidative stress and energy metabolism induced by LPS [26]. At present, in vivo and in vitro studies also indicated that HLJDD showed atopic dermatitis treatment effects. In 2,4-dinitrochlorobenzene-induced atopic dermatitis mice, HLJDD down-regulated serum expression levels of IL-1 $\alpha$, IL-1 $\beta$, IL-2, IL-4, IL-5, IL-6, interferongamma and TNF- $\alpha$, normalised the splenic $\mathrm{CD} 4^{+} / \mathrm{CD} 8^{+}$ T-lymphocyte ratio, and inactivated MAPKs (including p38, extracellular regulated protein kinases (ERK), and $\mathrm{c}$-Jun $\mathrm{N}$-terminal kinase (JNK)), I $\mathrm{KB}-\alpha$, and NF- $\mathrm{kB}$ (p65). Moreover, HLJDD inhibited LPS-induced differentiation of RAW264.7 cells, reduced LPS binding to the RAW264.7 cell membrane, as well as decreased ERK, p38, JNK, IKB- $\alpha$, and p65 phosphorylation levels in the MAPKs/NF-KB pathway and inhibited p65 nuclear translocation [115]. Further, a study revealed that HLJDD had a positive effect in rat gingivitis induced by LPS. HLJDD boosted the ability of anti-oxidation and anti-inflammatory by inhibiting AMPK and ERK pathways [116]. The molecular mechanisms of HLJDD regulating inflammation-related pathways are shown in Fig. 6.

According to the "Four-nature Theory", all Chinese herbs are fit into four categories, including "cold" "hot" "warm" and "cool" herbs. Based on this theory, the four herbs in HLJDD are all recognized as "heat-clearing" herbs, which means that they all have therapeutic powers of removing the "body fire". In classic Chinese philosophy, "fire", one of five "basic elements" (wood, fire, earth, metal and water), is an element with dual seemingly paradox roles as both beneficial and deleterious [117]. The excess "body fire" will exert deleterious impacts and form the basis of many diseases. In fact, the essence of "body fire" is a gradual process including oxidative/nitrosative stress, inflammation and infection. Oxidative stress can induce inflammation and many other diseases by disrupting normal cellular mechanisms. Infection is a form of invasion and multiplication of various infectious agents in body, which will also cause inflammation. Therefore, inflammation involves a greatly complex web of intercellular cytokine signals [118] and is related to the pathogenesis of most diseases, such as cancer, and CNS diseases mentioned in this review.

\section{Blood lipid and glucose-modulating}

Symptom-complex of wasting-thirst in TCM mainly refers to syndrome $\mathrm{X}$. According to the classical TCM theory, the pathogenesis of the metabolic syndrome is induced by excessive "heat" dissipating the body fluids. Moreover, recent researches on TCM theory pointed out that the internal heat is the primary pathogenic factor for the development of T2DM. In addition, excessive lipid may lead to the accumulation of "heat", which eventually transforms into toxin, a more serious cause.
The regulations of lipid are divided into several parts: reducing lipid synthesis; increasing lipid degradation; and combating damage caused by high levels of lipids, such as inducing inflammatory responses. In an apolipoprotein E knockout mouse model, HLJDD was found to markedly decrease the ratio of inflammatory subset of monocytes. In addition, the results from in vitro experiments indicated that HLJDD-containing serum significantly facilitated differentiation of M2 macrophages and foam cells. Thus, HLJDD might attenuate the development of atherosclerosis, probably by regulating the functional differentiation of monocytes, macrophages, and foam cells [119]. It was reported that HLJDD could activate the activity of lipoprotein lipase and hepatic lipase, and enhance the expressions of low-density lipoprotein receptor and peroxisome proliferator-activated receptor gamma mRNAs to modulate the lipid metabolism in high-fat diet-induced rats [14]. However, HLJDD contains various chemical components and might possess multiple mechanisms to modulate the lipid metabolism. Therefore, HLJDD may exert the hypolipidemic effect through other mechanisms. For example, using the olive oil loading test, Zhang et al. reported that HLJDD extract lowered total cholesterol, triglyceride, and low-density lipoprotein cholesterol level of T2DM rats by inhibiting intestinal pancreatic lipase activity [30]. It could be speculated that HLJDD might exert the effect of lipid-modulating by multi-targets, multi-pathways and multi-effects.

Insulin secretion and insulin action are essential for blood glucose homeostasis, and defects in either process cause metabolic diseases, such as T2DM [120, 121]. Furthermore, HLJDD could decrease blood glucose concentration and ameliorated diabetic syndrome partly through its interaction with intestinal tract [120]. Glucagon-like peptide 1 (GLP-1), an important incretin secreted by the gastrointestinal L-cells, enhances insulin secretion, improves $\beta$ cell proliferation and neogenesis, and reduces glucagon release from the pancreatic islet cells $[122,123]$. In the last decade, a novel group of glucose-lowering agents has been developed based on the gut hormone GLP-1 [124]. It was reported that 5-week HLJDD (4 g/kg/day) treatment on diabetic rats enhanced GLP-1 secretion in gut and the released GLP-1 subsequently promoted insulin secretion and improved function of $\beta$ cell in pancreas [120]. In an in vitro study, the water extracts of RS and HLJDD increased insulin secretion in Min6 cells and GLP-1 secretion in NCI-H716 cells by elevating intracellular cyclic adenosine monophosphate levels. RS and HLJDD also increased $\beta$ cell mass through hyperplasia and hypertrophy. The rise in hyperplasia was associated with elevated insulin receptor substrate 2 and pancreatic and duodenal homeobox 1 


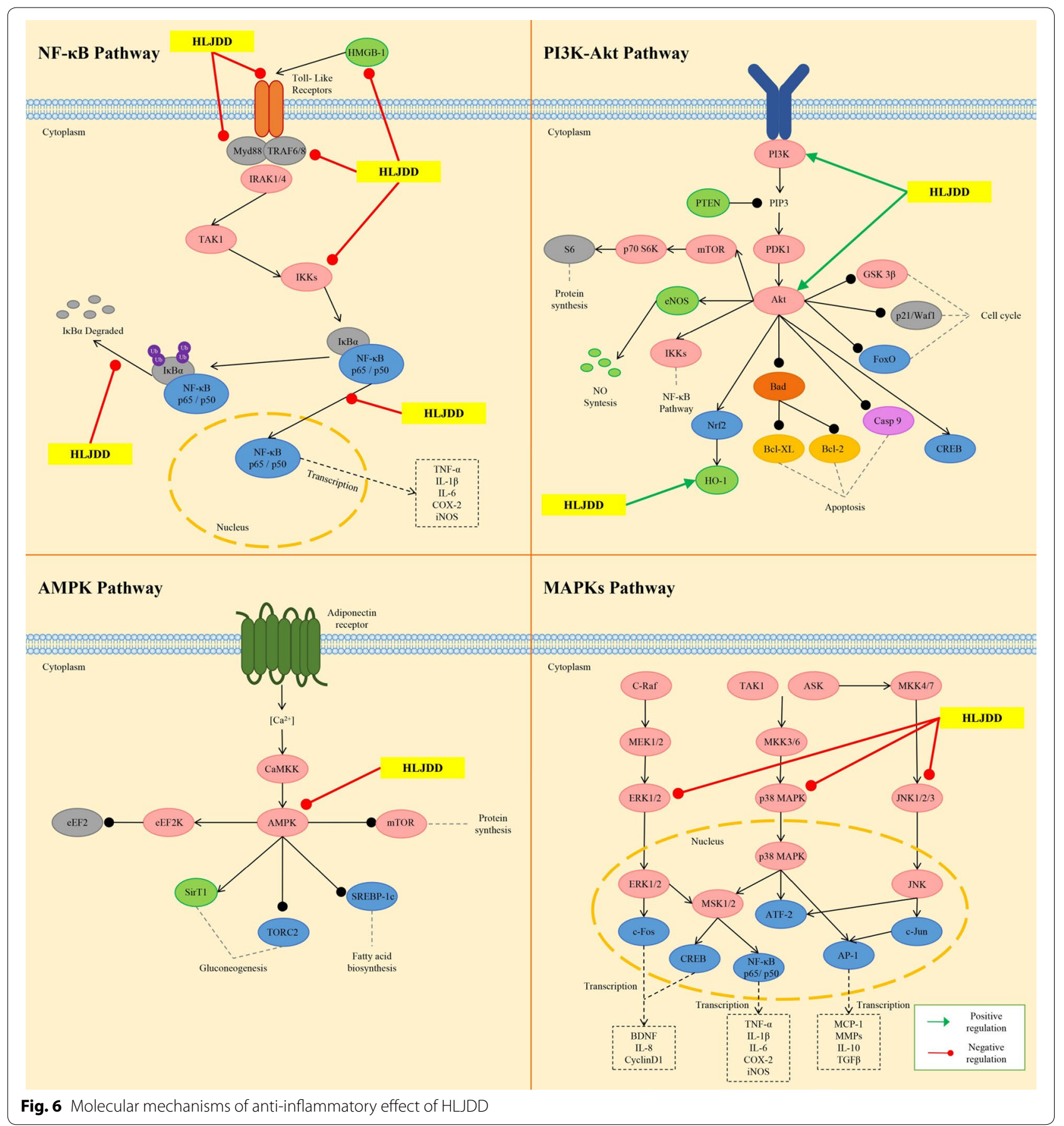

expression in the islets [121]. Geniposide, an active ingredient of HLJDD, has been reported as an agonist for GLP-1 receptor [125]. However, whether it can promote GLP-1 secretion is still unclear. Moreover, whether other compounds included in HLJDD contribute to the promotion of GLP-1 remains to be further investigated.

\section{Central nervous system diseases}

Diseases of central nervous system (CNS) are also believed to have close associations with the heat and toxins in TCM theory. The pathogenic factors, namely toxins, lead to nervous system injury, both in function and/or organic architecture. The typical clinical 
symptoms are dysfunction of learning and memory, mood disorder, psychosis, cerebrovascular diseases, etc.

Currently, considerable studies have been conducted to understand the pharmacological mechanisms of HLJDD on ischemia-induced brain damage. Preconditioning of HLJDD protected neurons against oxygen and glucose deprivation, significantly reduced the cerebral infarction volume and cerebral water content, and improved the neurological deficient score of model rats obtained through middle cerebral artery occlusion (MCAO). The activation of the phosphatidylinositol 3-kinase/ protein kinase B (Akt) signaling pathway and hypoxiainducible factor-1 alpha was proved to be responsible for the resistance of HLJDD to ischemia-reperfusion or hypoxia injury contribute to inhibiting neuron apoptosis and enhancing neuron proliferation [28]. Furthermore, it has been reported that HLJDD exerted neuroprotective effects on ischemic stroke partly though the Aktindependent protective autophagy via the regulation of MAPK signals, which can avoid unfavorable sideeffects associated with the inactivation of Akt [126]. Pattern analysis of the ${ }^{1} \mathrm{H}$ NMR data disclosed that HLJDD could relieve MCAO rats by ameliorating the disordered metabolisms in energy, membrane and mitochondrial, amino acid and neurotransmitter, alleviating the inflammatory damage and the oxidative stress from reactive oxygen species, and recovering the destructed osmoregulation [127]. Total alkaloids, iridoids and flavonoids from HLJDD have potential as a treatment for ischemic brain injury. Firstly, alkaloids treatment was found to enhance neurogenesis by increasing the expression of vascular endothelial growth factor, angiopoietin-1 (Ang1 ), and Ang-2 protein, and its neuroproliferative effect was partially correlated with enhanced phosphorylation of Akt, and glycogen synthase kinase-3 beta. Secondly, flavonoids could promote differentiation of cortical precursor cells into neuronal, which may be attributable to the regulation of Akt, glycogen synthase kinase-3 beta mRNA and Ang-1 protein levels. Finally, alkaloids and iridoids increased number of BrdU-positive cells and enhanced neuronal differentiation in the cortex [29]. Berberine, baicalin and gardenoside are the representative components of alkaloids, flavonoids and iridoids respectively, all of which can improve functional outcome after brain ischemia. Berberine exerted potent neuroprotective effects in ischemic environment [128]. Baicalin could also protect neuronal cells against various neurotoxic stimuli and ischemia-reperfusion injury [40]. Gardenoside was shown to enhance neurons viability, prompt neurite growth, and attenuate neuronal death against ischemic damage [129]. A study showed that the combination of these three ingredients treatment increased the levels of cellular antioxidants that scavenged reactive oxygen species during ischemia-reperfusion via the nuclear erythroid 2-related factor 2 signaling cascade, and exhibited stronger effects than the individual herbs alone [130]. Berberine and baicalin were the molecular basis for ameliorating the neurological function in ischemia-reperfusion, possibly due to their induction of increased expression of NF- $\kappa B$, inducible nitric oxide synthase and cyclooxygenase 2 protein. In addition, the combination of berberine and gardenoside possessed neuroprotective effects, which may be related to their regulation of oxidative stress and autophagy [131]. These results indicated that the synergistic effects of different components of HLJDD are responsible for the powerful effectiveness of HLJDD. Besides, HLJDD was proved to ameliorate neurodegenerative diseases, such as AD. Clinical signs of $\mathrm{AD}$ are characterized by the neuron loss and cognitive impairment. Modern pharmacological studies have showed that HLJDD could significantly modulate effects on age-related changes of the gene expressions in the hippocampus and cerebral cortex in SAMP8 model, which include genes that involved in different biological function and process: signal transduction (Dusp12, Rps6ka1, Rab26, Penk1, Nope, Leng8, Syde1, Phb, Def8, Ihpk1, Tac2, Pik3c2a), protein metabolism (Ttc3, Amfr, Prr6, Ube2d2), cell growth and development (Ngrn, Anln, Dip3b, Acrbp), nucleic acid metabolism (Fhit, Itm2c, Cstf2t, Ddx3x, Ercc5, Pcgfr6), energy metabolism (Stub1, Uqcr, Nsf), immune response (C1qb), regulation of transcription (D1ertd161e, Gcn512, Ssu72), transporter (Slc17a7, mt-Co1), nervous system development (Trim3), and neurogila cell differentiation (Tspan2) [132]. In APPswe/PS1dE9 mice, another classic animal model of AD, HLJDD had positive effects on AD by ameliorating neuroinflammation and sphingolipid metabolic disorder [34]. In addition, HLJDD may inhibit the activity of indoleamine 2,3-dioxygenase, one of the potential participants involved in the pathogenesis of $\mathrm{AD}$ [133].

The effects of HLJDD on CNS diseases are mainly through anti-inflammatory, antioxidant, and regulating energy metabolisms. At the same time, HLJDD also has different effects on central nervous functions and neurotransmitter levels. In a metabolomics study, HLJDD decreased the levels of glutamine and $\gamma$-aminobutyric acid in plasma of MACO rats, which might be responsible for neuronprotection via the decline of excitotoxicity of glutamate. HLJDD also elevated acetylcholine level and maintained cholinergic neurons function [27]. The molecular mechanisms of HLJDD in the treatment of CNS are shown in Fig. 7.

However, the role of HLJDD in the CNS should not be considered simply from the traditional pharmacological effects. New perspectives, such as regulating the liver and 


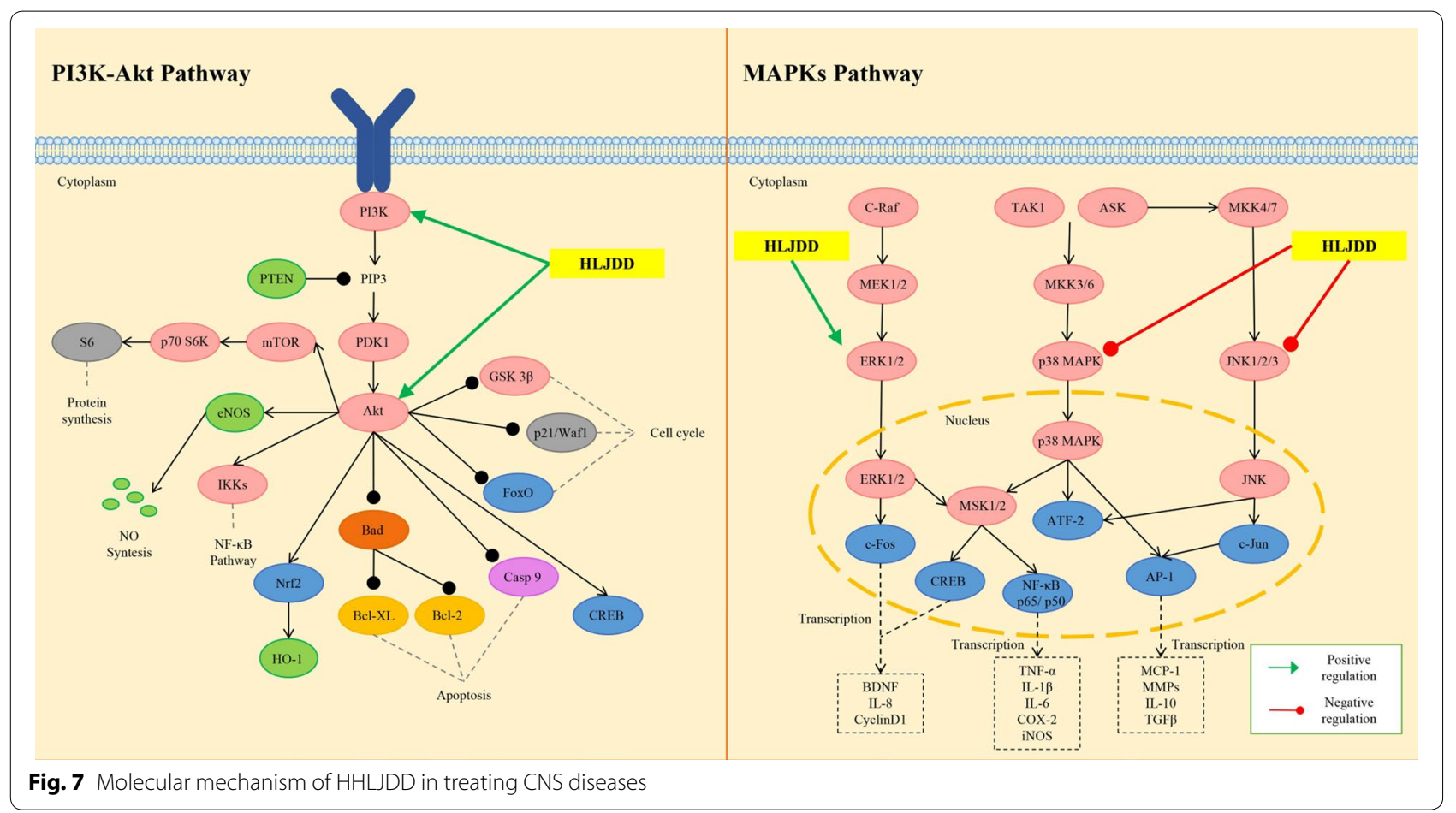

gut bacteria, should be given more attention. The former can regulate the CNS through the liver-brain axis, while the latter can further intervene the CNS by activating the brain-gut axis, especially in the case of mental system diseases. The inflammatory response of the CNS is an important link and target for the intervention of HLJDD in the CNS. Compounds that directly enter the brain tissue, as well as the liver-brain axis and the brain-gut axis, are the pathways for the effects of HLJDD. The regulation of energy metabolism, on one hand, has a direct antagonistic effect on the occurrence and development of cerebrovascular diseases. On the other hand, the adjustment of energy can also adjust the function and state of microglia to intervene inflammation.

\section{Anti-infection and microbiota-modulating}

Bacterial or virus infection or imbalance of bacteria in the body commonly stimulates inflammatory responses or immune activation resulting in redness, swelling, heat and pain directly or participates in the pathological development of various systems such as gastrointestinal tract, endocrine and CNS. Such diseases are covered, at least partly, by the theory of heat and toxins of TCM. The actions on bacteria or viruses are the focus of heat dissipation and detoxification treatments.

Candida albicans (C. albicans) is the most prevalent opportunistic fungal pathogen that can cause surface and even systemic infections in immunocompromised patients $[134,135]$. The results of gene expression of C. albicans with the treatment of HLJDD showed that ATP-binding cassette transporter and major facilitator superfamily transporter, which encode multidrug transporters, were identified to be remarkably upregulated, which might provide insights for the inhibition mechanism of HLJDD against C. albicans [35]. The ethyl acetate extract of HLJDD with concentration of $312 \mathrm{mg} / \mathrm{L}$ and $1250 \mathrm{mg} / \mathrm{L}$ could inhibit formation of hyphae and colony morphologies of $C$. albicans through downregulating the expression of hyphae-specific genes such as HWP1, ALS3, UME6 and CSH1 [136]. Pseudomonas aeruginosa, an opportunistic Gram-negative pathogen, has characteristic of quorum sensing modulation. HLJDD showed the lowest minimum inhibitory concentration (MIC) of $100 \mathrm{mg} / \mathrm{mL}$ against Pseudomonas aeruginosa, while MICs of $200 \mathrm{mg} / \mathrm{mL}$ for the RC and $\mathrm{RS}, 400 \mathrm{mg} / \mathrm{mL}$ for the CP, and more than $400 \mathrm{mg} / \mathrm{mL}$ for the FG. Moreover, at the sub-MIC, HLJDD significantly reduced pyocyanin pigment, elastolytic activity, proteolytic activity, biofilm formation, and bacterial motility [137]. In Mugil cephalus, 1\% modified HLJDD feeding for 28 days may prevent Lactococcus garvieae infection and could be used in aquaculture industries [138]. Moreover, the water extracts of HLJDD and its four herbs exerted potent treatment power on H1N1 infection through the inhibition of neuraminidase (NA) activity [139], which is one of the biomarkers 
for subtype classification of influenza $A$ virus. The $\mathrm{IC}_{50}$ of HLJDD, RC, RS, CP, FG, and peramivir (positive control) on NA activity were $112.6 \pm 6.7 \mu \mathrm{g} / \mathrm{mL}$ $96.1 \pm 7.6 \mu \mathrm{g} / \mathrm{mL}, 303.5 \pm 21.9 \mu \mathrm{g} / \mathrm{mL}, 108.6 \pm 8.6 \mu \mathrm{g} /$ $\mathrm{mL}, \quad 285.0 \pm 16.6 \mu \mathrm{g} / \mathrm{mL}$, and $478.8 \pm 15.6 \mu \mathrm{g} / \mathrm{mL}$, respectively. Accordingly, it is valuable to use HLJDD as a complementary medicine for $\mathrm{H} 1 \mathrm{~N} 1$ infection in clinical. In addition, based on the effective inhibitors of various NA subtypes of its active ingredients, such as berberine [140], coptisine [141], and baicalein [142], it is meaningful to further study the anti-viral effect of HLJDD.

In high-fat diet and streptozotocin-induced T2DM rats, HLJDD treatment ameliorated hyperglycemia and restored the disturbed gut microbiota structure and function to a nearly normal condition mainly through increasing short chain fatty acids-producing bacteria while reducing conditioned pathogenic bacteria [143].

Various chemical components in HLJDD have antiinfection effects, especially alkaloids, of which berberine has been used as a commodity for the treatment of bacterial diarrhea. For bacteria of different species, there are commonalities and differences between different components. At present, researches on bacteria cannot be limited to bacteriostatic or bactericidal. In view of the low bioavailability of chemical components, the effects of intestinal flora on the metabolism of compounds in HLJDD, as well as the evaluations of level and activity of metabolites need to be further studied. In a metabolomics study, 6 high level compounds in HLJDD [46], including 4 alkaloids (berberine, palmatine, coptisine and jatrorrhizine), 1 flavonoid (baicalin) and 1 iridoid (geniposide), were selected to clarify the metabolic pathways of HLJDD in rat urine and feces by LC-IT-MS combining with LC-FT-ICR-MS. In general, phase I (hydroxylation and demethylation) and phase II (sulfate conjugation and glucuronidated conjugation) reactions of flavonoids and iridoids, as well as phase I and II (hydroxylation, demethylation and glucuronidation) reactions of alkaloids were observed as the major metabolic fate of HLJDD in vivo. Notably, abundant benzylisoquinoline alkaloids were detected in feces due to their poor absorption in gastrointestinal tract. All the glucuronidated flavonoid glycosides were prototypes as well as metabolites [144]. It was reported that hydrolyzation by enterobacteria and subsequently glucuronidation reactions of flavonoids occurred in vivo [145]. In addition, the studies on the effects of the chemical components in HLJDD on the species abundance and metabolic activities of intestinal bacteria and the level of metabolites, such as neurotransmitters and short-chain fatty acids, may be new research ideas and directions to reveal the potential mechanisms and pathways of HLJDD.

\section{Other pharmacological effects}

Early studies showed that HLJDD could protect ethanol- and aspirin-induced gastric mucosal barrier injury [146], and gastric hemorrhagic lesions [147]. These gastric protection effects of HLJDD may be ascribed to the reinforcement of mucosal barrier resistance through endogenous sulfhydryl compounds and diethyldithiocarbamate-sensitive compounds [148, 149]. In addition, HLJDD could inhibit drug-stimulated gastric acid secretion [150] via dopamine receptors and alpha-2 adrenoceptors [151]. In clinical, modified HLJDD combined electroacupuncture could promote the recovery of gastrointestinal function in critically ill patients after abdominal surgery via improving intestinal barrier function [152]. In addition, the administration of HLJDD in combination with chlorpromazine would alleviated the side-effects caused by less dose [153], while the mechanism remains to be unknown.

\section{Pharmacokinetic investigation}

PK is a discipline which studies quantitatively the law of absorption, distribution, metabolism and excretion of drugs in vivo and expounds the law of blood drug concentration with time by applying mathematical principles and methods. PK investigation is of great significance in the new drug development, the studies of drug-induced toxicity, and drug interaction $[154,155]$. Reasonably, it is the pivotal approach to reveal the obscure pharmacodynamic properties and toxicity of herbals or formulas in TCM [156]. Commonly, LC-MS/MS [157], HPLC-MS/ MS [158], UPLC-MS/MS [159], and GC-MS [160] are the main techniques employed in PK investigation.

HLJDD is a traditional Chinese prescription with different types of PK interactions among its multi-components. In recent years, studies of the PK profiles and absorption of alkaloids, flavonoids and iridoid glycosides both in pure components and in HLJDD have been well conducted [38-41, 161-166], especially of berberine, baicalin and geniposide. Berberine had better absorption within HLJDD than that of solo compound in an intestinal perfusion model of rat [167]. Similar phenomena were observed in the study of investigating the differences of absorption of geniposide after oral administration of geniposide alone and HLJDD by PK studies in vivo, intestinal perfusion model, and Caco-2 model. In addition, geniposide had better absorption in the duodenum and jejunum through passive diffusion [168]. These results indicated that the intestinal absorption of berberine and geniposide were affected by compatibility of other compounds of HLJDD. Baicalin showed bimodal phenomenon in the plasma following oral administrations of pure baicalin and HLJDD in rats, and other components in HLJDD had PK interaction with baicalin 
[40]. There were few studies on the PK investigation of the whole HLJDD extracts. Ren et al. obtained systematic PK data concerning the activity of HLJDD under inflammatory conditions by LC-QqQ-MS using a dynamic multiple reaction monitoring method. In normal group, the $\mathrm{C}_{\max }$ of geniposide, magnolflorine, baicalin, berberine, oroxylin A-7-O-glucuronide, wogonoside, wogonin and oroxylin A were $0.7 \pm 0.3,0.6 \pm 0.2,0.09 \pm 0.03,0.6 \pm 0.4$, $0.09 \pm 0.03,0.11 \pm 0.04,0.09 \pm 0.03$, and $0.08 \pm 0.0 \mathrm{ng} / \mathrm{mL}$, respectively. And the mean residence time were $0.9 \pm 0.1$, $1.8 \pm 0.1,4.3 \pm 0.3,5.7 \pm 3.5,4.4 \pm 0.5,4.7 \pm 0.5,4.3 \pm 0.8$, $3.0 \pm 0.6 \mathrm{~h}$, respectively. Compared with the normal control group, the PK behaviors of alkaloids, flavonoids, and iridoids in the inflammatory model exhibited a trend of continuous changes, including higher bioavailability, slower elimination, delays in reaching the $C_{\max }$ and longer substantivity [169]. In addition, there were a handful of PK investigations of couplet medicines from HLJDD. Pan et al. explored the differences in PK and antioxidant effect of RC-FG couplet medicine and HLJDD in MCAO rats, which have been scarcely reported [170]. In MCAO group, the $C_{\max }$ of RC-FG and HLJDD were $1.188 \pm 0.162 \mathrm{mg} / \mathrm{L}$ and $1.44 \pm 50.295 \mathrm{mg} / \mathrm{L}$, respectively. The $T_{\max }$ of were $0.625 \pm 0.137 \mathrm{~h}$ and $0.458 \pm 0.188 \mathrm{~h}$, and the mean residence time were $97.042 \pm 34.642 \mathrm{~h}$ and $101.306 \pm 81.211 \mathrm{~h}$, respectively. The results illustrated that HLJDD, compared with RC-FG couplet medicine, had a better assimilation effect, higher peak concentration, shorter time to peak, slower elimination rate, and longer mean dwell time in the context of cerebral ischemia. In addition, the extremely low concentrations of gardenia acid and geniposide could not prevent the superoxide dismutase from returning to normal values. This phenomenon may be due to other ingredients such as flavonoids and alkaloids, which played a similar role as iridoids. It demonstrated that HLJDD exhibited the ability in treating cerebral ischemia through its three major constituents synergistically. In rat liver microsomes incubation system, total flavonoids and alkaloids extracts exibited strong inhibition on rat cytochrome P450 isoenzymes activities, while HLJDD aqueous extract and total iridoids extracts had moderate inhibition ability. Total flavonoids and alkaloids also exhibited significant inhibitory effect on P-glycoprotein activity as evidenced by the efflux of Rhodamine-123 with $\mathrm{IC}_{50}$ of 104.6 and $82.6 \mu \mathrm{g} /$ $\mathrm{mL}$. However, the HLJDD aqueous extract and total iridoids extracts showed weak and negligible inhibitory effect on P-glycoprotein activity, respectively [171]. For further studies of herb-herb interactions and human situation in vivo, PK studies involving human intestinal and liver microsome preparations should also be conducted.

Common analytical methods employed in PK studies usually need relatively large amounts of sample [172].
An indirect competitive enzyme-linked immunosorbent assay based on monoclonal antibodies against geniposide was developed and was successfully applied to study the PK of geniposide in HLJDD in mice [173]. Therefore, a technology with higher detection sensitivity would quite help in PK studies especially in small animals.

Compared with abundant data of pharmacology and chemical composition studies, PK studies cannot well support and interpret the pharmacological actions of HLJDD. On one hand, it is difficult to confirm the active components. Although some effective components such as berberine were known, their pharmacological effects cannot represent the whole TCM formula. Due to the limitations of analytical methods, on the other hand, simultaneous detection and analysis of all chemical components cannot be carried out. Therefore, it is necessary to combine with other methods. For example, according to the pharmacodynamic data, the main parameters are calculated to indicate changes in an active ingredient, a group of components, synergies between components, or interactions between metabolites.

\section{Conclusion}

It is well known that TCM formula is a complex system and combinations can make the prescriptions more suitable for clinical application through herb-herb synergic interactions that improve pharmacological activities. Different from the methodology and philosophy of western medicine, TCM focuses on the overall functional state of the patients and the adjustment of their balance, which has aroused ever-increasing interest worldwide, especially for the treatment of complex diseases [174]. HLJDD, a classic TCM formula to clear "heat" and "toxins", is an aqueous extract of four herbal materials, $\mathrm{RC}, \mathrm{RS}, \mathrm{CP}$, and FG in a ratio of 3:2:2:3. Although the four herbs show unique activities with varying abilities respectively, synergistic functions are exhibited when combining them in an appropriate proportion.

In this view, we summarize the phytochemical, pharmacological and PK investigations of HLJDD. The potential bioactive constituents of this formula can be classified as alkaloids, flavonoids, and iridoids. Among them, berberine, baicalin, and geniposide are the representative ingredients. Containing numerous compounds, HLJDD exhibits pharmacological activities in various aspects, including anti-tumer, hepatoprotection, antiinflammatory, anti-allergy, lipid-modulating, CNS diseases, anti-bacterial, and gut microbiota-modulating. The main differences between the PK profiles of primary ingredients in HLJDD and pure compounds are reflected in some important PK parameters. HLJDD tends to present higher $C_{\max }$, shorter $T_{\max }$ and better pharmacological effects than that in single drug or couplet medicine. 
These results demonstrate that the co-occurring components in HLJDD might interact with each other.

To further shed light on compositive principle and action characteristics of HLJDD, several obstacles that represent the common problems of TCM need to be conquered. Firstly, accurately annotating and understanding the classical literatures of the utilization of Chinese medicine formula combined with totally randomized blank controlled double-blind clinical trials would help to confirm the therapeutic effects and reveal the adverse reactions. Secondly, personalized medicine is the specific signature of TCM, according to which one formula might be adopted to treat different diseases with the similar syndromes. One kind of disease, however, might be treated with different formula due to variations in syndromes. Then, with the modern biological technologies and pharmacological approaches, the investigations on clinical syndromes and the following development of preclinical research system in cell or animal with consistent pathological features or biomarkers are expected to interpret of rationality and rule of compatibility of monarchs, ministers, assistants and ambassadors in the prescription of Chinese medicine, to reveal the concepts of TCM theories such as heat-clearing and detoxifying. Moreover, unlike Western medicine, therapeutic system of TCM is established directly on the clinical practices. But the complex constitutes of herbals make it hard to note the exact activating components and the interfered node of pathophysiological process. Abundant ingredients of herbs commonly bear the burden of therapeutic efficacy through activating or inhibiting different targets. Highthroughput screening on the targets associated with the representative signaling pathway and further pharmacological assay on the synergistic action of those chemicals are required to explore interaction network between the multiple components and the multiple targets. Novel form of TCM formula appearing as several chemical preparations is believed to substitute the primary formula, which could be endowed with typical chemical, pharmacological and pharmacokinetic features. Furthermore, based on these digital database resources, the interactions between the chemicals and targets and relationship between the targets need to be analyzed via the system pharmacology, which favors the prediction of the potential activate components and the underlying targets or signaling pathways of TCM formulas. The following work performed to validate these literature mining results includes transcriptomics, proteomics, metabolomics, and rigorous biochemics and pharmacologics. Finally, the exploration is always on for TCM formulas, which promote the determination of pivotal components and uncover the interesting pathological mechanisms in the context of positive clinical therapeutic effects.
The studies of TCM formula are based on thousands of years of clinical medication experience, which provides a guarantee for the direction of basic research. The basic researches can simplify the formula and enhance the targeting and specificity in the treatment of certain diseases. On the other hand, combined with the PK analysis, basic researches can explore meaningful monomer compounds. In addition, on the basis of pharmacological effect evaluation and molecular mechanism analysis, basic researches can develop new therapeutic compounds when combining with chemical synthesis technology. Finally, it is also worth noting that many disease markers, discovered because of their exact clinical value, could play a role in TCM formula where the active ingredients are not well defined and the treatment mechanisms are not clear. Therefore, the development of new compounds targeting these markers will provide effective research ideas and reliability assurance for the development of new drugs.

\section{Abbreviations}

HLJDD: Huang-Lian Jie-Du decoction; TCM: traditional Chinese medicine; RC: Rhizoma Coptidis; RS: Radix Scutellariae; CP: Cortex Phellodendri; FG: Fructus Gradeniae; T2DM: type 2 diabetes mellitus; AD: Alzheimer's disease; PK: pharmacokinetics; eEF2K: eukaryotic elongation factor-2 kinase; AMPK: AMP-activated protein kinase; mTOR: mammalian target of rapamycin; NF-kb: nuclear factor-kappa B; NO: nitric oxide; LO: lipoxygenases; LPS: lipopolysaccharide; IL: interleukin; TNF-a: tumor necrosis factor-alpha; IkB-a: inhibitor-kappa B-alpha; MAPK: mitogen-activated protein kinase; Th: T-helper; GLP-1: glucagon-like peptide 1; CNS: central nervous system; MCAO: middle cerebral artery occlusion; Akt: protein kinase B; Ang: angiopoietin; C. albicans: Candida albicans; MIC: minimum inhibitory concentrations; NA: neuraminidase.

\section{Acknowledgements}

Not applicable.

\section{Authors' contributions}

YQ draft the manuscript. QZ and HZ initiated the topic, revised and finally confirmed the manuscript. All authors read and approved the final manuscript.

\section{Funding}

This research was financially supported by the National Natural Science Foundation of China (Project Nos. 81573635; 81873027), the Qing-Lan Project of Jiangsu Province, the Open Project Program of Jiangsu Key Laboratory for Pharmacology and Safety Evaluation of Chinese Materia Medica (No. JKLPSE201820), the Project Funded by the Priority Academic Program Development of Jiangsu Higher Education Institutions (PAPD), the Project of the Innovation Research Team of Nanjing University of Chinese Medicine, and the Project Funded by the Six Talent Project in Jiangsu Province.

Availability of data and materials

Not applicable.

Ethics approval and consent to participate Not applicable.

Consent for publication

Not applicable.

Competing interests

The authors declare that they have no competing interests. 


\begin{abstract}
Author details
1 Jiangsu Collaborative Innovation Center of Chinese Medicinal Resources Industrialization, Nanjing University of Chinese Medicine, Nanjing, China.

2 Jiangsu Key Laboratory for High Technology Research of TCM Formulae, Nanjing University of Chinese Medicine, Nanjing, China. ${ }^{3}$ Jiangsu Research Center of Botanical Medicine Refinement Engineering, Nanjing University of Chinese Medicine, Nanjing, China. ${ }^{4}$ Department of Pharmacology, Pharmacy College, Nanjing University of Chinese Medicine, Nanjing, China.
\end{abstract}

Received: 25 July 2019 Accepted: 3 December 2019

Published online: 18 December 2019

\section{References}

1. Xiong X, Che CT, Borrelli F, Moudgil KD, Caminiti G. Evidence-based TAM classic herbal formula: from myth to science. Evid Based Complement Alternat Med. 2017;2017:9493076.

2. Liu XJ, Su SB. Study of combination methods for formula composition of Chinese herbal medicines and their components. Zhong Xi Yi Jie He Xue Bao. 2009;7(7):601-6.

3. Wu Y, Sun J, Shi R, Zhang A. Effect of Huanglian Jiedu tang active fraction on calcium overloading in neurons and related mechanism analysis. Zhongguo Zhong Yao Za Zhi. 2010;35(16):2166-70.

4. Xu D, Lv Y, Wang J, Yang M, Kong L. Deciphering the mechanism of Huang-Lian-Jie-Du-Decoction on the treatment of sepsis by formula decomposition and metabolomics: enhancement of cholinergic pathways and inhibition of HMGB-1/TLR4/NF-kappaB signaling. Pharmacol Res. 2017:121:94-113.

5. Wang L, Zhou GB, Liu P, Song JH, Liang Y, Yan XJ, Xu F, Wang BS, Mao JH, Shen ZX, et al. Dissection of mechanisms of Chinese medicinal formula Realgar-Indigo naturalis as an effective treatment for promyelocytic leukemia. Proc Natl Acad Sci USA. 2008;105(12):4826-31.

6. Wang N, Feng Y, Tan HY, Cheung F, Hong M, Lao L, Nagamatsu T. Inhibition of eukaryotic elongation factor-2 confers to tumor suppression by a herbal formulation Huanglian-Jiedu decoction in human hepatocellular carcinoma. J Ethnopharmacol. 2015;164:309-18.

7. Oshima N, Narukawa Y, Hada N, Kiuchi F. Quantitative analysis of antiinflammatory activity of orengedokuto: importance of combination of flavonoids in inhibition of PGE2 production in mouse macrophage-like cell line J774.1. J Nat Med. 2013;67(2):281-8.

8. Okamoto H, Chino A, Hirasaki Y, Ueda K, lyo M, Namiki T. Orengedokuto augmentation in cases showing partial response to yokukan-san treatment: a case report and literature review of the evidence for use of these Kampo herbal formulae. Neuropsychiatr Dis Treat. 2013;9:151-5.

9. Tanaka K, Nara K, Nishimura T, Serizawa K, Miyazaki T, Urita Y, Miura O. Fever of unknown origin successfully treated by oren-gedoku-to (huanglian-jie-du-tang). Int J Gen Med. 2013;6:829-32.

10. Zhen HS, Chen Y, Zhong XJ. Quality standards of huanglian jiedu pills. Zhongguo Zhong Yao Za Zhi. 1994;19(7):414-7.

11. Zeng H, Dou S, Zhao J, Fan S, Yuan X, Zhu S, Li L, Zhang W, Liu R. The inhibitory activities of the components of Huang-Lian-Jie-Du-Tang (HLJDT) on eicosanoid generation via lipoxygenase pathway. J Ethnopharmacol. 2011;135(2):561-8.

12. Kim NK, Lee DH, Seo HS, Sun SH, Oh YL, Kim JE, Yoon IH, Seo ES, Shim GS, Zaslawski C. Hwangryunhaedoktang in adult patients with atopic dermatitis: a randomised, double-blind, placebo-controlled, two-centre trial—study protocol. BMC Complement Altern Med. 2011;11:68.

13. Okumi $\mathrm{H}$, Koyama A. Kampo medicine for palliative care in Japan. Biopsychosoc Med. 2014;8(1):6.

14. Jin J, Zhang Y, Hu WX, Zhang ZY, Xu NN, Zhou QL. Effects of Huanglian Jiedu Decoction on blood lipid metabolism and its related gene expressions in rats with hyperlipidemia. Zhong Xi Yi Jie He Xue Bao. 2010:8(3):275-9.

15. Sun J, Wen QH, Song Y, Li X, Jin J, Ma JS, Zhou QL. Study on antitumor activities of huanglian jiedu decoction. Zhongguo Zhong Yao Za Zhi. 2006;31(17):1461-3.

16. Lin LT, Wu SJ, Lin CC. The anticancer properties and apoptosisinducing mechanisms of cinnamaldehyde and the herbal prescription
Huang-Lian-Jie-Du-Tang (Huang Lian Jie Du Tang) in human hepatoma cells. J Tradit Complement Med. 2013;3(4):227-33.

17. Zhang H, Fu P, Ke B, Wang S, Li M, Han L, Peng C, Zhang W, Liu R. Metabolomic analysis of biochemical changes in the plasma and urine of collagen-induced arthritis in rats after treatment with Huang-LianJie-Du-Tang. J Ethnopharmacol. 2014;154(1):55-64.

18. Yue R, Zhao L, Hu Y, Jiang P, Wang S, Xiang L, Liu W, Zhang W, Liu R. Rapid-resolution liquid chromatography TOF-MS for urine metabolomic analysis of collagen-induced arthritis in rats and its applications. J Ethnopharmacol. 2013;145(2):465-75.

19. Yue R, Zhao L, Hu Y, Jiang P, Wang S, Xiang L, Liu W, Shan L, Zhang W, Liu R. Metabolomic study of collagen-induced arthritis in rats and the interventional effects of huang-lian-jie-du-tang, a traditional Chinese medicine. Evid Based Complement Alternat Med. 2013;2013:439690.

20. Ma ST, Feng CT, Dai GL, Song Y, Zhou GL, Zhang XL, Miao CG, Yu H, Ju WZ. In silico target fishing for the potential bioactive components contained in Huanglian Jiedu Tang (HLDD) and elucidating molecular mechanisms for the treatment of sepsis. Chin J Nat Med. 2015;13(1):30-40.

21. Liao ST, Li P, Wang JS, Zhang Q, Xu DQ, LV Y, Yang MH, Kong L. Huang-Lian-Jie-Du decoction treated sepsis via regulating ERK and SRC/STAT3 pathways and ameliorating metabolic status. Rsc Adv. 2016;6(92):89855-66.

22. Wei Y, Gao N, Zhang Z, Zu X, Hu Z, Zhang W, Yin J, Liu X. Metabolic changes at the early stage of sepsis induced by cecal ligation and puncture in rats and the interventional effects of HuangLian-Jie-Du-Tang. J Chromatogr B Analyt Technol Biomed Life Sci. 2016;1026:176-82.

23. Li CB, Li XX, Chen YG, Gao HQ, Bu PL, Zhang Y, Ji XP. Huang-lian-jiedu-tang protects rats from cardiac damages induced by metabolic disorder by improving inflammation-mediated insulin resistance. PLoS ONE. 2013;8(6):e67530.

24. Wei DD, Wang JS, Duan JA, Kong LY. Metabolomic assessment of acute cholestatic injuries induced by thioacetamide and by Bile Duct Ligation, and the protective effects of Huang-Lian-Jie-Du-decoction. Front Pharmacol. 2018;9:458.

25. Wei DD, Liao ST, Wang JS, Yang MH, Kong LY. Cholestatic liver injury model of bile duct ligation and the protection of HuangLian-Jie-Du decoction by NMR metabolomic profiling. Rsc Adv. 2015;5(81):66200-11.

26. Li P, Liao ST, Wang JS, Zhang Q, Xu DQ, Lv Y, Yang MH, Kong LY. Protection by Huang-Lian-Jie-Du decoction and its constituent herbs of lipopolysaccharide-induced acute kidney injury. FEBS Open Bio. 2017;7(2):221-36

27. Zhu BJ, Cao HT, Sun LM, Li B, Guo LW, Duan JA, Zhu HX, Zhang QC. Metabolomics-based mechanisms exploration of Huang-Lian Jie-Du decoction on cerebral ischemia via UPLC-Q-TOF/MS analysis on rat serum. J Ethnopharmacol. 2018;216:147-56.

28. Zhang Q, Bian H, Li Y, Guo L, Tang Y, Zhu H. Preconditioning with the traditional Chinese medicine Huang-Lian-Jie-Du-Tang initiates HIF1alpha-dependent neuroprotection against cerebral ischemia in rats. J Ethnopharmacol. 2014;154(2):443-52.

29. Zou H, Long J, Zhang Q, Zhao H, Bian B, Wang Y, Zhang J, Zhao H, Wang L. Induced cortical neurogenesis after focal cerebral ischemia - three active components from Huang-Lian-Jie-Du Decoction. J Ethnopharmacol. 2016;178:115-24.

30. Zhang XJ, Deng YX, Shi QZ, He MY, Chen B, Qiu XM. Hypolipidemic effect of the Chinese polyherbal Huanglian Jiedu decoction in type 2 diabetic rats and its possible mechanism. Phytomedicine. 2014;21(5):615-23.

31. He MY, Deng YX, Shi QZ, Zhang XJ, LV Y. Comparative pharmacokinetic investigation on baicalin and wogonoside in type 2 diabetic and normal rats after oral administration of traditional Chinese medicine Huanglian Jiedu decoction. J Ethnopharmacol. 2014;155(1):334-42.

32. Durairajan SS, Huang YY, Yuen PY, Chen LL, Kwok KY, Liu LF, Song JX, Han QB, Xue L, Chung SK, et al. Effects of Huanglian-Jie-Du-Tang and its modified formula on the modulation of amyloid-beta precursor protein processing in Alzheimer's disease models. PLoS ONE. 2014;9(3):e92954.

33. Yu D, Tao BB, Yang YY, Du LS, Yang SS, He XJ, Zhu YW, Yan JK, Yang Q. The IDO inhibitor coptisine ameliorates cognitive impairment in a mouse model of Alzheimer's disease. J Alzheimers Dis. 2015;43(1):291-302. 
34. Sun LM, Zhu BJ, Cao HT, Zhang XY, Zhang QC, Xin GZ, Pan LM, Liu LF, Zhu HX. Explore the effects of Huang-Lian-Jie-Du-Tang on Alzheimer's disease by UPLC-QTOF/MS-based plasma metabolomics study. J Pharm Biomed Anal. 2018;151:75-83.

35. Yang $\mathrm{Q}$, Gao L, Tao M, Chen Z, Yang X, Cao Y. Transcriptomics analysis of Candida albicans treated with Huanglian Jiedu decoction using RNAseq. Evid Based Complement Alternat Med. 2016;2016:3198249.

36. Oshima N, Shimizu T, Narukawa Y, Hada N, Kiuchi F. Quantitative analysis of the anti-inflammatory activity of orengedokuto II: berberine is responsible for the inhibition of NO production. J Nat Med 2018;72(3):706-14.

37. Hu Y, Jiang P, Wang S, Yan S, Xiang L, Zhang W, Liu R. Plasma pharmacochemistry based approach to screening potential bioactive components in Huang-Lian-Jie-Du-Tang using high performance liquid chromatography coupled with mass spectrometric detection. J Ethnopharmacol. 2012;141(2):728-35.

38. Deng YX, LuT, Xie L, Liu XD. High-performance liquid chromatographic method for the determination and pharmacokinetic study of wogonoside in rat serum after oral administration of traditional Chinese medicinal preparation Huang-Lian-Jie-Du decoction. Biomed Chromatogr. 2006:20(10):1098-102.

39. Lu T, Liang Y, Song J, Xie L, Wang GJ, Liu XD. Simultaneous determination of berberine and palmatine in rat plasma by HPLC-ESI-MS after oral administration of traditional Chinese medicinal preparation HuangLian-Jie-Du decoction and the pharmacokinetic application of the method. J Pharm Biomed Anal. 2006;40(5):1218-24.

40. Lu T, Song J, Huang F, Deng Y, Xie L, Wang G, Liu X. Comparative pharmacokinetics of baicalin after oral administration of pure baicalin, Radix scutellariae extract and Huang-Lian-Jie-Du-Tang to rats. J Ethnopharmacol. 2007;110(3):412-8.

41. Zeng MF, Pan LM, Zhu HX, Zhang QC, Guo LW. Comparative pharmacokinetics of baicalin in plasma after oral administration of HuangLian-Jie-Du-Tang or pure baicalin in MCAO and sham-operated rats. Fitoterapia. 2010;81(6):490-6.

42. Zhu H, Qian Z, Li H, Guo L, Pan L, Zhang Q, Tang Y. Integrated pharmacokinetics of major bioactive components in MCAO rats after oral administration of Huang-Lian-Jie-Du-Tang. J Ethnopharmacol. 2012:141(1):158-69.

43. Sun J, Ma JS, Jin J, Wang HS, Wen QH, Zhang HG, Zhou QL. Qualitative and quantitative determination of the main components of huanglianjiedu decoction by HPLC-UV/MS. Yao Xue Xue Bao. 2006;41 (4):380-4.

44. Lu J, Wang JS, Kong LY. Anti-inflammatory effects of Huang-Lian-Jie-Du decoction, its two fractions and four typical compounds. J Ethnopharmacol. 2011;134(3):911-8.

45. Kwok KY, Xu J, Ho HM, Chen HB, Li M, Lang Y, Han QB. Quality evaluation of commercial Huang-Lian-Jie-Du-Tang based on simultaneous determination of fourteen major chemical constituents using high performance liquid chromatography. J Pharm Biomed Anal. 2013;85:239-44.

46. Yang $Y$, Wang $H J$, Yang J, Brantner AH, Lower-Nedza AD, Si N, Song $J F$, Bai B, Zhao HY, Bian BL. Chemical profiling and quantification of Chinese medicinal formula Huang-Lian-Jie-Du decoction, a systematic quality control strategy using ultra high performance liquid chromatography combined with hybrid quadrupole-orbitrap and triple quadrupole mass spectrometers. J Chromatogr A. 2013;1321:88-99.

47. Jiang L, Xiong Y, Yu L, Chen Y, Zhang Q, Ding X, Yan X, Nie P, Xu G. Simultaneous determination of seven active components in rat plasma by UHPLC-MS/MS and application to a quantitative study after oral administration of Huang-Lian Jie-Du decoction in high fat-induced atherosclerosis rats. Int J Anal Chem. 2019;2019:5628160.

48. Kobayashi Y, Yamashita Y, Fujii N, Takaboshi K, Kawakami T, Kawamura M, Mizukami T, Nakano H. Inhibitors of DNA topoisomerase I and II isolated from the Coptis rhizomes. Planta Med. 1995;61 (5):414-8.

49. Chen J, Wang F, Liu J, Lee FS, Wang X, Yang H. Analysis of alkaloids in Coptis chinensis Franch by accelerated solvent extraction combined with ultra performance liquid chromatographic analysis with photodiode array and tandem mass spectrometry detections. Anal Chim Acta. 2008;613(2):184-95.

50. Li XG, Yang LG, Chen LX, Qiu F. Chemical constituents from the decoction of Coptis chinensis Franch. J Shenyang Pharm Univ. 2012;29(3):193-8.
51. Ma HM, Chen G, Li W, Fan XM, Li ZF, Pei YH. Isolation and identification of chemical constituents from rhizoma of Coptis chinensis. J Shenyang Pharm Univ. 2011;28(9):695-9.

52. Wang L, Zhang SY, Chen L, Huang XJ, Zhang QW, Jiang RW, Yao F, Ye WC. New enantiomeric isoquinoline alkaloids from Coptis chinensis, Phytochem Lett. 2014;7:89-92.

53. Qin MJ, Wang HQ. Studies on chemical constituents of Phellodendron Chinense Schneid Bark. Chem Indus For Prod. 2003;23(4):42-6.

54. Xian X, Sun B, Ye X, Zhang G, Hou P, Gao H. Identification and analysis of alkaloids in cortex Phellodendron amurense by high-performance liquid chromatography with electrospray ionization mass spectrometry coupled with photodiode array detection. J Sep Sci. 2014;37(13):1533-45

55. Min YD, Yang MC, Lee KH, Kim KR, Choi SU, Lee KR. Protoberberine alkaloids and their reversal activity of P-gp expressed multidrug resistance (MDR) from the rhizome of Coptis japonica Makino. Arch Pharm Res. 2006;29(9):757-61.

56. Chen HY, Ye XL, Cui XL, He K, Jin YN, Chen Z, Li XG. Cytotoxicity and antihyperglycemic effect of minor constituents from Rhizoma Coptis in HepG2 cells. Fitoterapia. 2012:83(1):67-73.

57. Teng $\mathrm{H}$, Choi YH. Optimization of ultrasonic-assisted extraction of bioactive alkaloid compounds from rhizoma coptidis (Coptis chinensis Franch.) using response surface methodology. Food Chem. 2014;142:299-305.

58. Lv X, Li Y, Tang C, Zhang Y, Zhang J, Fan G. Integration of HPLC-based fingerprint and quantitative analyses for differentiating botanical species and geographical growing origins of Rhizoma coptidis. Pharm Biol. 2016;54(12):3264-71.

59. Dai SY, Xu B, Zhang Y, Li JY, Sun F, Shi XY, Qiao YJ. Establishment and reliability evaluation of the design space for HPLC analysis of six alkaloids in Coptis chinensis (Huanglian) using Bayesian approach. Chin J Nat Med. 2016;14(9):697-708.

60. Liu L, Chen Z. Analysis of four alkaloids of Coptis chinensis in rat plasma by high performance liquid chromatography with electrochemical detection. Anal Chim Acta. 2012;737:99-104.

61. Jiang $X$, Huang LF, Wu LB, Wang ZH, Chen SL. UPLC-QTOF/MS analysis of alkaloids in traditional processed Coptis chinensis Franch. Evid Based Complement Alternat Med. 2012;2012:942384.

62. Gao X, Yang X, Mitrevski BS, Marriott PJ. Headspace solid-phase microextraction combined with GCXGC-TOFMS for the analysis of volatile compounds of Coptis species rhizomes. J Sep Sci. 2011:34(10):1157-66.

63. Hou Y, Wu T, Liu Y, Wang H, Chen Y, Chen B, Sun W. Direct analysis of quaternary alkaloids by in situ reactive desorption corona beam ionization MS. Analyst. 2014;139(20):5185-91.

64. Yi L, Liang ZT, Peng Y, Guo P, Wong LL, Wan XJ, Ho HM, Yi T, Zhao ZZ. Histochemical evaluation of alkaloids in rhizome of Coptis chinensis using laser microdissection and liquid chromatography/mass spectrometry. Drug Test Anal. 2015;7(6):519-30.

65. Liu Q, Qiu S, Yu H, Ke Y, Jin Y, Liang X. Selective separation of structurerelated alkaloids in Rhizoma coptidis with "click" binaphthyl stationary phase and their structural elucidation with liquid chromatographymass spectrometry. Analyst 2011:136(20):4357-65.

66. Zuo F, Nakamura N, Akao T, Hattori M. Pharmacokinetics of berberine and its main metabolites in conventional and pseudo germ-free rats determined by liquid chromatography/ion trap mass spectrometry. Drug Metab Dispos. 2006;34(12):2064-72.

67. Horvath CR, Martos PA, Saxena PK. Identification and quantification of eight flavones in root and shoot tissues of the medicinal plant huanggin (Scutellaria baicalensis Georgi) using high-performance liquid chromatography with diode array and mass spectrometric detection. J Chromatogr A. 2005;1062(2):199-207.

68. Wei Y, Wang SY, Wu SY, Kang C, Li YF. Qualitative characterization of flavonoids in Scutellariae Radix by using PREC-IDA-EPI. Zhongguo Zhong Yao Za Zhi. 2018:43(2):345-52

69. Zhou XQ, Liang H, Lu XH, Cai SQ, Wang B, Zhao YY. Flavonoids from Scutellaria baicalensis and their bioactivities. Beijing Da Xue Xue Bao Yi Xue Ban. 2009:41(5):578-84

70. Chen L, Wang L, Zhang Q, Zhang S, Ye W. Non-alkaloid chemical constituents from Coptis chinensis. Zhongguo Zhong Yao Za Zhi. 2012:37(9):1241-4. 
71. Wang HZ, Yu CH, Gao J, Zhao GR. Effects of processing and extracting methods on active components in Radix Scutellariae by HPLC analysis. Zhongguo Zhong Yao Za Zhi. 2007;32(16):1637-40.

72. Gu XR, Fang SY, Ren W, Wang HJ, Yang J, Si N, Bian BL, Zhao HY. Pharmacodynamics of Huanglian Jiedu decoction in Alzheimer's disease (AD) model rats and effect on improvement of inflammation microenvironment in brain. Zhongguo Zhong Yao Za Zhi. 2018;43(14):3006-11.

73. Seo MJ, Hong JM, Kim SJ, Lee SM. Genipin protects d-galactosamine and lipopolysaccharide-induced hepatic injury through suppression of the necroptosis-mediated inflammasome signaling. Eur J Pharmacol. 2017:812:128-37.

74. Zhou X, Chen C, Ye X, Song F, Fan G, Wu F. Study of separation and identification of the active ingredients in gardenia jasminoides ellis based on a two-dimensional liquid chromatography by coupling reversed phase liquid chromatography and hydrophilic interaction liquid chromatography. J Chromatogr Sci. 2017;55(1):75-81.

75. He WH, Liu XA, Xu HG, Gong Y, Yuan F, Gao YX. On-line HPLC-ABTS screening and HPLC-DAD-MS/MS identification of free radical scavengers in Gardenia (Gardenia jasminoides Ellis) fruit extracts. Food Chem. 2010;123(2):521-8.

76. Zhou T, Zhao W, Fan G, Chai Y, Wu Y. Isolation and purification of iridoid glycosides from Gardenia jasminoides Ellis by isocratic reversed-phase two-dimensional preparative high-performance liquid chromatography with column switch technology. J Chromatogr B Analyt Technol Biomed Life Sci. 2007:858(1-2):296-301.

77. Lee EJ, Hong JK, Whang WK. Simultaneous determination of bioactive marker compounds from Gardeniae fructus by high performance liquid chromatography. Arch Pharm Res. 2014;37(8):992-1000.

78. Zhao SJ, Yang Y, Liang DX, Liang DZ, Zhang C. Quantitative analysis of geniposide in fructus Gardeniae and its different processed products. Zhongguo Zhong Yao Za Zhi. 1994;19(10):601-2.

79. Chen GC, Li XL, Chen G. Isolation and identification of lignans chemical constituents from Coptis chinensis and their inhibitory activity to protein tyrosine phosphatase-1B. Chin Pharm. 2016;27:2197-200.

80. Meng FC, Wang L, Zhang J, Yin ZQ, Zhang QW, Ye WC. Non-alkaloid chemical constituents from the rhizome of Coptis teeta. J Chin Pharm Univ. 2013:44(4):307-10

81. Li ZF, Wang Q, Feng YL, Yan YB, Fan MM, Yang SL. Chemical constituents in Coptis chinensis Franch. Chin New Drug J. 2012;21(13):1551-3.

82. Li ZF, Wang Q, Feng YL, Rao Y, Yang SL, Pei YH. Chemical constituents from rhizomes of Coptis chinensis. Chin Tradit Herbal Drugs. 2012;43(7):1273-5.

83. Ma HM, Chen G, Pei YH. Isolation and identification of chemical constituents from rhizoma of Coptis chinensis and their cytotoxic activities. J Shenyang Pharm Univ. 2013;30(10):759-63.

84. Dai SJ, Tao JY, Liu K, Jiang YT, Shen L. neo-Clerodane diterpenoids from Scutellaria barbata with cytotoxic activities. Phytochemistry. 2006;67(13):1326-30.

85. Yang GC, Hu JH, Li BL, Liu H, Wang JY, Sun LX. Six new neo-clerodane diterpenoids from aerial parts of Scutellaria barbata and their cytotoxic activities. Planta Med. 2018;84(17):1292-9.

86. Song SH, Wang ZZ. Analysis of essential oils from different organs of Scutellaria baicalensis. Zhong Yao Cai. 2010;33(8):1265-70.

87. Yuan YF, Tao ZH, Liu JX, Tian CH, Wang GW, Li YQ. Identification of Cortex Phellodendri by Fourier-transform infrared spectroscopy and principal component analysis. Guang Pu Xue Yu Guang Pu Fen Xi. 2011;31(5):1258-61.

88. Hu YM, Su GH, Sze SC, Ye W, Tong Y. Quality assessment of Cortex Phellodendri by high-performance liquid chromatography coupled with electrospray ionization mass spectrometry. Biomed Chromatogr. 2010;24(4):438-53.

89. Zhang Q, Cai L, Zhong G, Luo W. Simultaneous determination of jatrorrhizine, palmatine, berberine, and obacunone in Phellodendri Amurensis Cortex by RP-HPLC. Zhongguo Zhong Yao Za Zhi. 2010;35(16):2061-4.

90. Wang L, Yan G, Zhang A, Shi H, Sun H, Wang X. Fingerprinting and simultaneous determination of alkaloids and limonins in Phellodendri amurensis cortex from different locations by high-performance liquid chromatography with diode array detection. J Chromatogr Sci. 2015;53(1):161-6.
91. Wang L, Liu S, Zhang X, Xing J, Liu Z, Song F. A strategy for identification and structural characterization of compounds from Gardenia jasminoides by integrating macroporous resin column chromatography and liquid chromatography-tandem mass spectrometry combined with ion-mobility spectrometry. J Chromatogr A. 2016;1452:47-57.

92. Ni Y, Li L, Zhang W, Lu D, Zang C, Zhang D, Yu Y, Yao X. Discovery and LC-MS characterization of new crocins in gardeniae fructus and their neuroprotective potential. J Agric Food Chem. 2017;65:2936-46.

93. Liu H, Yao L, Chen JH, Gu XZ, Ma YL, Chen Y, Li PL, Zhang C. Analysis of volatile ingredients in Gardeniae Fructus and its processed products by GC-MS. Zhongguo Zhong Yao Za Zhi. 2015;40(9):1732-7.

94. Bressac B, Galvin KM, Liang TJ, Isselbacher KJ, Wands JR, Ozturk M. Abnormal structure and expression of p53 gene in human hepatocellular carcinoma. Proc Natl Acad Sci USA. 1990:87(5):1973-7.

95. Kaul G, Pattan G, Rafeequi T. Eukaryotic elongation factor-2 (eEF2): its regulation and peptide chain elongation. Cell Biochem Funct. 2011;29(3):227-34.

96. Shin S, Wolgamott L, Tcherkezian J, Vallabhapurapu S, Yu Y, Roux PP, Yoon SO. Glycogen synthase kinase-3beta positively regulates protein synthesis and cell proliferation through the regulation of translation initiation factor 4E-binding protein 1. Oncogene. 2014;33(13):1690-9.

97. Sataranatarajan K, Mariappan MM, Lee MJ, Feliers D, Choudhury GG, Barnes $J$, Kasinath BS. Regulation of elongation phase of mRNA translation in diabetic nephropathy: amelioration by rapamycin. Am J Pathol. 2007;171(6):1733-42

98. Lv X, Yu X, Wang Y, Wang F, Li H, Wang Y, Lu D, Qi R, Wang H. Berberine inhibits doxorubicin-triggered cardiomyocyte apoptosis via attenuating mitochondrial dysfunction and increasing $\mathrm{BCl}-2$ expression. PLOS ONE. 2012;7(10):e47351.

99. Ma Y, Yang F, Wang Y, Du Z, Liu D, Guo H, Shen J, Peng H. CaMKKbeta is involved in AMP-activated protein kinase activation by baicalin in LKB1 deficient cell lines. PLoS ONE. 2012;7(10):e47900.

100. Hsu YL, Kuo PL, Tzeng TF, Sung SC, Yen MH, Lin LT, Lin CC. Huanglian-jie-du-tang, a traditional Chinese medicine prescription, induces cell-cycle arrest and apoptosis in human liver cancer cells in vitro and in vivo. J Gastroenterol Hepatol. 2008:23(7 Pt 2):e290-9.

101. Ma Z, Otsuyama K, Liu S, Abroun S, Ishikawa H, Tsuyama N, Obata M, Li FJ, Zheng X, Maki Y, et al. Baicalein, a component of Scutellaria radix from Huang-Lian-Jie-Du-Tang (HLJDT), leads to suppression of proliferation and induction of apoptosis in human myeloma cells. Blood. 2005;105(8):3312-8

102. Hideshima T, Mitsiades C, Akiyama M, Hayashi T, Chauhan D, Richardson P, Schlossman R, Podar K, Munshi NC, Mitsiades N, et al. Molecular mechanisms mediating antimyeloma activity of proteasome inhibitor PS-341. Blood. 2003;101(4):1530-4

103. Chen CJ, Raung SL, Liao SL, Chen SY. Inhibition of inducible nitric oxide synthase expression by baicalein in endotoxin/cytokine-stimulated microglia. Biochem Pharmacol. 2004;67(5):957-65.

104. Beyoglu D, Idle JR. The metabolomic window into hepatobiliary disease. J Hepatol. 2013;59(4):842-58.

105. Lv Y, Wang J, Xu D, Liao S, Li P, Zhang Q, Yang M, Kong L. Comparative study of single/combination use of Huang-Lian-Jie-Du decoction and berberine on their protection on sepsis induced acute liver injury by NMR metabolic profiling. J Pharm Biomed Anal. 2017;145:794-804.

106. Zeng H, Liu X, Dou S, Xu W, Li N, Liu X, Zhang W, Hu Z, Liu R. HuangLian-Jie-Du-Tang exerts anti-inflammatory effects in rats through inhibition of nitric oxide production and eicosanoid biosynthesis via the lipoxygenase pathway. J Pharm Pharmacol. 2009;61(12):1699-707.

107. Hu Y, Hu Z, Wang S, Dong X, Xiao C, Jiang M, Lv A, Zhang W, Liu R. Protective effects of Huang-Lian-Jie-Du-Tang and its component group on collagen-induced arthritis in rats. J Ethnopharmacol. 2013;150(3):1137-44.

108. Chen Y, Xian Y, Lai Z, Loo S, Chan WY, Lin ZX. Anti-inflammatory and anti-allergic effects and underlying mechanisms of Huang-Lian-Jie-Du extract: implication for atopic dermatitis treatment. J Ethnopharmacol. 2016;185:41-52.

109. Zhou H, Mineshita S. The effect of Oren-gedoku-to on experimental colitis in rats. J Pharm Pharmacol. 1999:51(9):1065-74.

110. Ohta Y, Kobayashi T, Nishida K, Nagata M, Ishiguro I. Therapeutic effect of Oren-gedoku-to extract on stress-induced acute gastric mucosal lesions in rats. Phytother Res. 1999;13(7):588-92. 
111. Ohta Y, Kobayashi T, Nishida K, Sasaki E, Ishiguro I. Preventive effect of Oren-gedoku-to (Huanglian-Jie-Du-Tang) extract on the development of stress-induced acute gastric mucosal lesions in rats. J Ethnopharmacol. 1999;67(3):377-84.

112. Wei Y, Shan L, Qiao L, Liu R, Hu Z, Zhang W. Protective Effects of Huang-Lian-Jie-Du-Tang against polymicrobial sepsis induced by cecal ligation and puncture in rats. Evid Based Complement Alternat Med. 2013;2013:909624

113. Chen G, Xu Y, Jing J, Mackie B, Zheng X, Zhang X, Wang J, Li X. The antisepsis activity of the components of Huanglian Jiedu Decoction with high lipid A-binding affinity. Int Immunopharmacol. 2017;46:87-96.

114. Chen GR, Zhang G, Li MY, Jing J, Wang J, Zhang X, Mackie B, Dou DQ The effective components of Huanglian Jiedu decoction against sepsis evaluated by a lipid A-based affinity biosensor. J Ethnopharmacol. 2016;186:369-76.

115. Fan HJ, Zhao XS, Tan ZB, Liu B, Xu HL, Wu YT, Xie LP, Bi YM, Lai YG, Liang $\mathrm{HF}$, et al. Effects and mechanism of action of Huang-Lian-Jie-Du-Tang in atopic dermatitis-like skin dysfunction in vivo and in vitro. J Ethnopharmacol. 2019;240:111937

116. Zhang F, Geng Y, Zhao H, Wang H, Zhang Y, Li D, Bian B, Yang H. Effects of Huanglian Jiedu decoration in rat gingivitis. Evid Based Complement Alternat Med. 2018;2018:8249013.

117. Li Y, Xie J, Li Y, Yang Y, Yang L. Literature data based systems pharmacology uncovers the essence of "body fire" in traditional Chinese medicine: a case by Huang-Lian-Jie-Du-Tang. J Ethnopharmacol. 2019;237:266-85.

118. Han J, Ulevitch RJ. Limiting inflammatory responses during activation of innate immunity. Nat Immunol. 2005;6(12):1198-205.

119. LiT, Han JY, Wang BB, Chen B, Li YM, Yu ZJ, Xue X, Zhang JP, Wang $X \mathrm{~B}$, Zeng $\mathrm{H}$, et al. Huanglian jiedu decoction regulated and controlled differentiation of monocytes, macrophages, and foam cells: an experimental study. Zhongguo Zhong Xi Yi Jie He Za Zhi. 2014;34(9):1096-102.

120. Yu YL, Lu SS, Yu S, Liu YC, Wang P, Xie L, Wang GJ, Liu XD. Huang-lian-jiedu-decoction modulates glucagon-like peptide-1 secretion in diabetic rats. J Ethnopharmacol. 2009;124(3):444-9.

121. Park S, Hong SM, Ahn IS, Kim YJ, Lee JB. Huang-Lian-Jie-Du-Tang supplemented with Schisandra chinensis Baill. and Polygonatum odoratum Druce improved glucose tolerance by potentiating insulinotropic actions in islets in 90\% pancreatectomized diabetic rats. Biosci Biotechnol Biochem. 2009:73(11):2384-92.

122. van Baar MJB, van der Aart AB, Hoogenberg K, Joles JA, Heerspink HJL, van Raalte $\mathrm{DH}$. The incretin pathway as a therapeutic target in diabetic kidney disease: a clinical focus on GLP-1 receptor agonists. Ther Adv Endocrinol Metab. 2019;10:2042018819865398.

123. Arulmozhi DK, Portha B. GLP-1 based therapy for type 2 diabetes. Eur J Pharm Sci. 2006;28(1-2):96-108

124. Nauck M. Incretin therapies: highlighting common features and differences in the modes of action of glucagon-like peptide-1 receptor agonists and dipeptidyl peptidase-4 inhibitors. Diabetes Obes Metab. 2016;18(3):203-16.

125. Liu J, Zheng X, Yin F, Hu Y, Guo L, Deng X, Chen G, Jiajia J, Zhang H. Neurotrophic property of geniposide for inducing the neuronal differentiation of PC12 cells. Int J Dev Neurosci. 2006:24(7):419-24

126. Wang PR, Wang JS, Zhang C, Song XF, Tian N, Kong LY. Huang-LianJie-Du-Decotion induced protective autophagy against the injury of cerebral ischemia/reperfusion via MAPK-mTOR signaling pathway. J Ethnopharmacol. 2013;149(1):270-80.

127. Wang PR, Wang JS, Yang MH, Kong LY. Neuroprotective effects of Huang-Lian-Jie-Du-Decoction on ischemic stroke rats revealed by (1)H NMR metabolomics approach. J Pharm Biomed Anal. 2014;88:106-16.

128. Zhang X, Zhang X, Wang C, Li Y, Dong L, Cui L, Wang L, Liu Z, Qiao H, Zhu $C$, et al. Neuroprotection of early and short-time applying berberine in the acute phase of cerebral ischemia: up-regulated pAkt, pGSK and $\mathrm{pCREB}$, down-regulated NF-kappaB expression, ameliorated BBB permeability. Brain Res. 2012;1459:61-70.

129. Nam KN, Choi YS, Jung HJ, Park GH, Park JM, Moon SK, Cho KH, Kang C, Kang I, Oh MS, et al. Genipin inhibits the inflammatory response of rat brain microglial cells. Int Immunopharmacol. 2010;10(4):493-9.

130. Zhang Q, Wang J, Zhang C, Liao S, Li P, Xu D, Lv Y, Yang M, Kong L. The components of Huang-Lian-Jie-Du-Decoction act synergistically to exert protective effects in a rat ischemic stroke model. Oncotarget. 2016;7(49):80872-87.

131. Zhang Q, Fu X, Wang J, Yang M, Kong L. Treatment effects of ischemic stroke by berberine, baicalin, and jasminoidin from Huang-Lian-Jie-DuDecoction (HLJDD) explored by an integrated metabolomics approach. Oxid Med Cell Longev. 2017;2017:9848594.

132. Zheng Y, Cheng XR, Zhou WX, Zhang YX. Gene expression patterns of hippocampus and cerebral cortex of senescence-accelerated mouse treated with Huang-Lian-Jie-Du decoction. Neurosci Lett. 2008:439(2):119-24

133. Yu CJ, Zheng MF, Kuang CX, Huang WD, Yang Q. Oren-gedoku-to and its constituents with therapeutic potential in Alzheimer's disease inhibit indoleamine 2,3-dioxygenase activity in vitro. J Alzheimers Dis. 2010;22(1):257-66

134. Linares CE, Giacomelli SR, Altenhofen D, Alves SH, Morsch VM, Schetinger MR. Fluconazole and amphotericin-B resistance are associated with increased catalase and superoxide dismutase activity in Candida albicans and Candida dubliniensis. Rev Soc Bras Med Trop. 2013;46(6):752-8

135. Zhang L, Yan K, Zhang Y, Huang R, Bian J, Zheng C, Sun H, Chen Z, Sun $N$, An R, et al. High-throughput synergy screening identifies microbial metabolites as combination agents for the treatment of fungal infections. Proc Natl Acad Sci USA. 2007;104(11):4606-11.

136. Wang TM, Yan YY, Shi GX, Xia D, Shao J, Wang CZ. Inhibitory effects of ethyl acetate extract of Huanglian Jiedu decoction on hyphae development of Candida albicans. Zhongguo Zhong Yao Za Zhi. 2014;39(24):4834-8

137. Xia F, Ye L, Wang P, Zhang M. Influence of Huang Lian Jie Du decoction on quorum sensing system of Pseudomonas aeruginosa. Altern Ther Health Med. 2018;24(1):21-9.

138. Choi WM, Lam CL, Mo WY, Cheng Z, Mak NK, Bian ZX, Wong MH. Effects of the modified Huanglian Jiedu decoction on the disease resistance in grey mullet (Mugil cephalus) to Lactococcus garvieae. Mar Pollut Bull. 2014;85(2):816-23.

139. Zhou X, Li H, Shi Z, Gao S, Wei S, Li K, Wang J, Li J, Wang R, Gong M, et al. Inhibition activity of a traditional Chinese herbal formula Huang-LianJie-Du-Tang and its major components found in its plasma profile on neuraminidase-1. Sci Rep. 2017;7(1):15549.

140. Wu Y, Li JQ, Kim YJ, Wu J, Wang Q, Hao Y. In vivo and in vitro antiviral effects of berberine on influenza virus. Chin J Integr Med. 2011;17(6):444-52.

141. Kim JH, Ryu YB, Lee WS, Kim YH. Neuraminidase inhibitory activities of quaternary isoquinoline alkaloids from Corydalis turtschaninovii rhizome. Bioorg Med Chem. 2014;22(21):6047-52.

142. Hour MJ, Huang SH, Chang CY, Lin YK, Wang CY, Chang YS, Lin CW. Baicalein, ethyl acetate, and chloroform extracts of Scutellaria baicalensis inhibit the neuraminidase activity of pandemic 2009 H1N1 and seasonal influenza A viruses. Evid Based Complement Alternat Med. 2013;2013:750803.

143. Chen M, Liao Z, Lu B, Wang M, Lin L, Zhang S, Li Y, Liu D, Liao Q, Xie Z. Huang-Lian-Jie-Du-decoction ameliorates hyperglycemia and insulin resistant in association with gut microbiota modulation. Front Microbiol. 2018:9:2380.

144. Zuo R, Ren W, Bian BL, Wang HJ, Wang YN, Hu H, Zhao HY, Si N. Metabolic fate analysis of Huang-Lian-Jie-Du decoction in rat urine and feces by LC-IT-MS combining with LC-FT-ICR-MS: a feasible strategy for the metabolism study of Chinese medical formula. Xenobiotica. 2016;46(1):65-81.

145. Lai MY, Hsiu SL, Chen CC, Hou YC, Chao PD. Urinary pharmacokinetics of baicalein, wogonin and their glycosides after oral administration of Scutellariae Radix in humans. Biol Pharm Bull. 2003;26(1):79-83.

146. Takase H, Miura O, Ito K. Pharmacological studies of some blended traditional Chinese medicines on gastric functions. (1). The effects of orengedoku-to (OGT), san'o-syasin-to (SST), antyu-san (AS) and dai-saiko-to (DST) on ethanol- and aspirin-induced injury of gastric mucosal barrier. Nihon Yakurigaku Zasshi. 1987:89(5):299-306.

147. Takase H, Imanishi K, Miura O, Yumioka E, Watanabe H. Pharmacological studies on the effects of some traditional Chinese medicines on gastric functions. (3) The effects of oren-gedoku-to (OGT), san'o-syasin-to (SST), antyu-san (AS) and dai-saiko-to (DST) on ethanol- and aspirin-induced gastric lesions in rats. Nihon Yakurigaku Zasshi. 1988;91(5):319-24. 
148. Takase H, Inoue O, Saito Y, Yumioka E, Suzuki A. Roles of sulfhydryl compounds in the gastric mucosal protection of the herb drugs composing oren-gedoku-to (a traditional herbal medicine). Jpn J Pharmacol. 1991;56(4):433-9.

149. Takase H, Imanishi K, Miura O, Yumioka E. A possible mechanism for the gastric mucosal protection by oren-gedoku-to (OGT), a traditional herbal medicine. Jpn J Pharmacol. 1989;51(1):17-23.

150. Takase H, Imanishi K, Miura O, Yumioka E, Watanabe H. Pharmacological studies of some traditional Chinese medicines on gastric functions. (2) The effects of oren-gedoku-to (OGT), san'o-syasin-to (SST), antyu-san (AS) and dai-saiko-to (DST) on gastric acid secretion in rats. Nihon Yakurigaku Zasshi. 1988;91(5):309-17.

151. Takase H, Tatsumi Y, Miura O, Yumioka E, Suzuki A. The mechanism of the inhibitory effects of oren-gedoku-to (OGT) on gastric acid secretion in rats. Nihon Yakurigaku Zasshi. 1991;97(2):97-103.

152. Wang L, Zhu HY, He JZ, Yin X, Guo LH. Effect of modified Huanglian Jiedu Decoction purgation Combined electroacupuncture in intervening gastrointestinal dysfunction of critically ill patients undergoing abdominal surgery. Zhongguo Zhong Xi Yi Jie He Za Zhi. 2015;35(8):966-70.

153. Sasaki K, Yoshizaki F, Nagasue M, Ando T. Effect of Oren-gedoku-to on changes in hexobarbital-induced sleeping time in chlorpromazinetreated mice. Yakugaku Zasshi. 1994;114(6):431-4.

154. Rowland M, Peck C, Tucker G. Physiologically-based pharmacokinetics in drug development and regulatory science. Annu Rev Pharmacol Toxicol. 2011;51:45-73.

155. Barrett YC, Wang J, Song Y, Pursley J, Wastall P, Wright R, LaCreta F, Frost C. A randomised assessment of the pharmacokinetic, pharmacodynamic and safety interaction between apixaban and enoxaparin in healthy subjects. Thromb Haemostasis. 2012;107(5):916-24.

156. Duan K, Yuan Z, Guo W, Meng Y, Cui Y, Kong D, Zhang L, Wang N. LC-MS/MS determination and pharmacokinetic study of five flavone components after solvent extraction/acid hydrolysis in rat plasma after oral administration of Verbena officinalis L. extract. J Ethnopharmacol. 2011;135(2):201-8.

157. Wang Z, Song M, Cui B, Ren Y, Zhu W, Yang B, Kuang H. A LC-MS/ MS method for simultaneous determination of seven alkaloids in rat plasma after oral administration of Phellodendri chinensis cortex extract and its application to a pharmacokinetic study. J Sep Sci. 2019;42(7):1351-63

158. Son H, Noh K, Kang C, Na M, Oh S, Song IS, Kang W. HPLC-MS/MS analysis of ilimaquinone and its application in a pharmacokinetic study in rats. J Pharm Biomed Anal. 2019;166:291-4.

159. Yang X, Zan T, Yan H, Liu B. UPLC-MS/MS determination of flavokawain $B$, a novel anti-tumor chemotherapeutic agent in rat plasma and its application to a pharmacokinetic study in rats. Biomed Chromatogr. 2019;33(2):e4391.

160. Yan H, Sun Y, Ma Y, Ji B, Hou X, Yu Z, Zhao Y. Determination of atractylon in rat plasma by a GC-MS method and its application to a pharmacokinetic study. J Pharm Anal. 2015;5(5):327-31.

161. Ma ZT, Yang XW, Zhang Y, Liu JX. Pharmacochemistry and integrated pharmacokinetics of six alkaloids after oral administration of huanglian-jie-du-tang decoction. J Asian Nat Prod Res. 2014;16(5):483-96.

162. Wu X, Peng J, Fan B, Yu Y. Pharmacokinetics of three alkaloids in Huanglianjiedu decoction in rat serum by LC-MS-MS. Zhongguo Zhong Yao Za Zhi. 2009;34(10):1276-80.
163. Kim YH, Jeong DW, Kim YC, Sohn DH, Park ES, Lee HS. Pharmacokinetics of baicalein, baicalin and wogonin after oral administration of a standardized extract of Scutellaria baicalensis, PF-2405 in rats. Arch Pharm Res. 2007;30(2):260-5.

164. Kotani A, Kojima S, Hakamata H, Kusu F. HPLC with electrochemical detection to examine the pharmacokinetics of baicalin and baicalein in rat plasma after oral administration of a Kampo medicine. Anal Biochem. 2006;350(1):99-104.

165. Pan L, Wang W, Shi F, Zhou J, Zhang M, Zhu H, Zeng M. Exploratory pharmacokinetics of geniposide in rat model of cerebral ischemia orally administered with or without baicalin and/or berberine. Evid Based Complement Alternat Med. 2013;2013:349531.

166. Zhang ZQ, Liua W, Zhuang L, Wang J, Zhang S. Comparative pharmacokinetics of baicalin, wogonoside, baicalein and wogonin in plasma after oral administration of pure baicalin, radix scutellariae and scutellariae-paeoniae couple extracts in normal and ulcerative colitis rats. Iran J Pharm Res. 2013;12(3):399-409.

167. Zhang Y, Zhu HX, Guo LW. Intestinal absorption of berberine alone and in combinations by rats single pass intestinal perfusion in situ. Yao Xue Xue Bao. 2012;47(2):233-8.

168. Yu D, Zhang Y, Guo L, Zhang Q, Zhu H. Study on the absorption mechanism of geniposide in the Chinese formula Huang-Lian-Jie-Du-Tang in rats. AAPS PharmSciTech. 2017;18(4):1382-92.

169. Ren W, Zuo R, Wang YN, Wang HJ, Yang J, Xin SK, Han LY, Zhao HY, Han SY, Gao B, et al. Pharmacokinetic-pharmacodynamic analysis on inflammation rat model after oral administration of Huang Lian Jie Du Decoction. PLoS ONE. 2016;11(6):e0156256.

170. Pan L, Zhou J, Zhu H, Wang W, Zhang M, Tian X, Lu J, Zeng M. Study on integrated pharmacokinetics of gardenia acid and geniposide: timeantioxidant efficacy after oral administration of Huanglian-Zhizi couplet medicine from Huang-Lian-Jie-Du-Tang in MCAO rats. Am J Chin Med. 2014;42(2):393-407.

171. Wang $Y$, Jiang $Y M$, Wang $Y T$, Kang JW, Yu T, Zhao HY, Bian BL, Huang $M$, Bi HC. Inhibiton of cytochrome P450 isoenzymes and P-gp activity by multiple extracts of Huang-Lian-Jie-Du decoction. J Ethnopharmacol. 2014;156:175-81.

172. Ying XX, Wang F, Cheng ZZ, Zhang WJ, Li HB, Du Y, Liu X, Wang SY, Kang TG. Pharmacokinetics of vitexin-4"-O-glucoside in rats after intravenous application. Eur J Drug Metab Pharmacokinet. 2012;37(2):109-15.

173. Qu HH, Sun Y, Wu TT, Zhang GL, Cheng JJ, Wang XQ, Feng HB, Zhao Y, Wang QG. Pharmacokinetics of geniposide by monoclonal antibodybased icELISA in mice after oral administration of Huanglian-Jiedu-Tang. Biol Pharm Bull. 2014;37(9):1525-33.

174. Jiang WY. Therapeutic wisdom in traditional Chinese medicine: a perspective from modern science. Trends Pharmacol Sci. 2005;26(11):558-63.

\section{Publisher's Note}

Springer Nature remains neutral with regard to jurisdictional claims in published maps and institutional affiliations.

Ready to submit your research? Choose BMC and benefit from:

- fast, convenient online submission

- thorough peer review by experienced researchers in your field

- rapid publication on acceptance

- support for research data, including large and complex data types

- gold Open Access which fosters wider collaboration and increased citations

- maximum visibility for your research: over $100 \mathrm{M}$ website views per year

At BMC, research is always in progress.

Learn more biomedcentral.com/submissions 